\title{
Early Upper Paleolithic chronology in the Levant: new ABOx-SC accelerator mass spectrometry results from the Mughr el-Hamamah Site, Jordan
}

\section{Authors}

Aaron Jonas Stutz ${ }^{\text {a, b, }{ }^{*} \text {, John J. Shea }}{ }^{\text {, }}$, Jason A. Rech ${ }^{\text {d }}$, Jeffrey S. Pigati ${ }^{\text {e }}$, Jim Wilson ${ }^{\text {f }}$, Miriam Belmaker $^{\mathrm{g}}$, Rosa Maria Albert ${ }^{\mathrm{h}, \mathrm{i}}$, Trina Arpin ${ }^{\mathrm{j}}$, Dan Cabanes ${ }^{\mathrm{i}}$, Jamie L. Clark ${ }^{\mathrm{k}}$, Gideon Hartman $^{1}$, Fuad Hourani ${ }^{\mathrm{m}}$, Chantel E. White ${ }^{\mathrm{n}}$, Liv Nilsson Stutz ${ }^{\mathrm{b}}$

${ }^{a}$ Department of Anthropology, Oxford College of Emory University, 810 Whatcoat St., Oxford, GA 30054 USA

${ }^{\mathrm{b}}$ Department of Anthropology, Emory University, 207 Anthropology Building, 1557 Dickey Dr., Atlanta, GA 30322 US

${ }^{\mathrm{c}}$ Anthropology Department, Stony Brook University, Stony Brook, NY 11794-4364 USA

${ }^{\mathrm{d}}$ Department of Geology, Miami University, Oxford, OH 45056 USA

${ }^{\mathrm{e}}$ U.S. Geological Survey, Denver Federal Center, Box 25046, MS-980, Denver, Colorado 80225

USA

${ }^{\mathrm{f}}$ Aeon Laboratories, LLC, 5835 N Genematas Dr, Tucson, AZ 85704-5919 USA

${ }^{\mathrm{g}}$ Department of Anthropology, Harwell Hall, Room 105, The University of Tulsa, Tulsa, Oklahoma 74104 USA

${ }^{\mathrm{h}}$ ICREA, University of Barcelona, c/ Montalegre, 6-8, 08001 Barcelona SPAIN

${ }^{\mathrm{i}}$ ERAAUB/Department of Prehistory, Ancient History and Archaeology, University of Barcelona, c/ Montalegre, 6-8, 08001 Barcelona SPAIN

${ }^{\mathrm{j}}$ Independent Researcher, PO Box 15587, Boston, MA 02215 
${ }^{\mathrm{k}}$ Department of Anthropology, University of Alaska Fairbanks, 303 Tanana Loop, Bunnell

Building Room 405A, Fairbanks, AK 99775-7720 USA

${ }^{1}$ Department of Anthropology, Unit 2176, 354 Mansfield Road, University of Connecticut, Storrs, CT 06269 USA

${ }^{\mathrm{m}}$ Institute of Archaeology, University of Jordan, Amman JORDAN

${ }^{\mathrm{n}}$ Department of Anthropology, University of Notre Dame, Flanner Hall, Notre Dame, IN 465565611 USA

* Corresponding author.

E-mail address: astutz@emory.edu

\begin{abstract}
Methodological developments and new paleoanthropological data remain jointly central to clarifying the timing and systemic interrelationships between the Middle-Upper Paleolithic (MP-UP) archaeological transition and the broadly contemporaneous anatomically modern human-archaic biological turnover. In the recently discovered cave site of Mughr el-Hamamah, Jordan, in situ flint artifacts comprise a diagnostic early Upper Paleolithic (EUP) assemblage.
\end{abstract}


Unusually well-preserved charcoal from hearths and other anthropogenic features associated with the lithic material were subjected to acid-base-wet oxidation-stepped combustion (ABOxSC) pretreatment. This article presents the ABOx-SC accelerator mass spectrometry (AMS) radiocarbon dates on nine charcoal specimens from a single palimpsest occupation layer. Date calibration was carried out using the INTCAL13 radiocarbon calibration dataset. With the bulk of the material dating to 45-39 ka cal BP (thousands of years calibrated before present), the Mughr el-Hamamah lithic artifacts reveal important differences from penecontemporaneous sites in the region, documenting greater technological variability than previously known for this time frame in the Levant. The radiocarbon data from this EUP archaeological context highlight remaining challenges for increasing chronological precision in documenting the MP-UP transition.

Keywords: Middle-Upper Paleolithic Transition; Biocultural Evolution; Radiocarbon Dating; ABOx-SC Pretreatment; AMS 


\section{Introduction}

The early Upper Paleolithic (EUP) in the Levant is broadly dated to ca. 50-30 ka (ka= thousands of calibrated ${ }^{14} \mathrm{C}$ years before present; Goring-Morris et al., 2009; Bar-Yosef and Belfer-Cohen, 2010; Shea, 2013; Stutz, 2014). Yet, it remains methodologically challenging to obtain accurate and precise radiometric dates on in situ samples from late Middle Paleolithic (LMP) and EUP deposits, especially for those older than ca. 40 ka (Douka et al., 2010; Brock and Higham, 2011; Pinhasi et al., 2011; Rech et al., 2011; Zilhão, 2013). This study presents new acid-base-wet oxidation-stepped combustion (ABOx-SC) pretreated accelerator mass

spectrometry (AMS) ${ }^{14} \mathrm{C}$ dates on charcoal from the recently discovered EUP cave site of Mughr el-Hamamah, Jordan (Caves of the Doves, hereafter MHM). Test excavations and preliminary analyses at MHM have revealed a diagnostic EUP lithic assemblage associated with a single prehistoric archaeological layer (Stutz et al., 2012). With preservation of a large archaeofaunal assemblage, abundant charred botanical remains, stratified combustion features, bone tools, and a small number of in situ isolated hominin remains, the EUP archaeology of MHM has potential to shed new light on the biocultural and environmental factors connecting the Levantine MiddleUpper Paleolithic transition to the wider western Eurasian development of anatomically modern human-Neandertal biological turnover in the 50-30 ka timeframe. With cross-disciplinary analyses ongoing, the MHM radiocarbon results contextualize preliminary observations on the chipped-stone artifacts, sampled from the entirety of the Upper Pleistocene palimpsest occupation layer. Although the ongoing lithic analysis may possibly reveal variation through time within the MHM deposits, the geoarchaeological observations in the field provide a contextual frame of a single EUP layer-lithologically defined-whose associated lithic 
technological features may be compared with those from other dated LMP and EUP sites across western Eurasia.

\section{The Mughr el-Hamamah site and its early Upper Paleolithic context}

Mughr el-Hamamah is located in the western portion of the Ajlun Governate, Jordan, situated roughly at $80 \mathrm{~m}$ above sea level (asl) (Fig. 1). It consists of five caves that have formed on the right (northeastern) bank of a minor, unnamed wadi between the major Wadis Rajib (to the south) and Kufrinja (to the north) (Fig. 2). Cave 2 is the largest extant karstic cavity at the MHM site, and it is the only cave within this complex to exhibit significant sedimentary deposits.

Insert Figures 1, 2 approximately here

Formed in a local Cenomanian limestone member, the five MHM caves are located approximately 30-40 $\mathrm{m}$ above the wadi floor, offering a commanding view of the Jordan Valley. During most of Marine Oxygen Isotope Stage 3 (hereafter, MIS 3, ca. 60-35 ka), MHM would have overlooked Lake Lisan (Lisker et al., 2009; Torfstein et al., 2013). However, during the lake's low levels within MIS 3 (ca. 48-45 ka and 39-38 ka, associated with Heinrich events 5 and 4, respectively), occupants of MHM would likely have viewed wetlands and open-vegetation terrain to the west and Lisan to the southwest (Bartov et al., 2002; Lisker et al., 2009; Torfstein et al., 2013). Within a $5 \mathrm{~km}$ radius mobile foragers occupying MHM would have had access to the Jordan Valley bottom, nearby major wadis with permanently flowing streams, and ridge-top paths toward upland resources. The ecotonal location on the eastern slopes of the Jordan Valley was within the lower margins of what then included more extensive Mediterranean forest habitat (Table 1). Preliminary surveys carried out in 2009 revealed that local flint is highly fractured and often has inclusions or cavities. These lithic raw materials are abundant throughout the Wadis 
Rajib and Kufrinja. However, high quality flint is readily available $10 \mathrm{~km}$ to the north and south, with additional high quality sources located in the uplands $20-30 \mathrm{~km}$ to the east.

Insert Table 1 approximately here

\section{Test excavations}

Following survey, initial mapping, and surface collection (Lovell, 2009; Richter et al., 2009), excavations were carried out by AJS, LNS, TA, and JLC during June and July 2010. This work included two test trenches inside Cave 2, totaling $8 \mathrm{~m}^{2}$ (Fig. 3). An additional $1 \mathrm{x} 1 \mathrm{~m}$ test pit was excavated just outside the Cave 2 dripline. Evidence of recent erosion and infilling just beyond the dripline led us to focus on the excavations inside Cave 2. The June-July 2010 test excavations at MHM Cave 2 were carried out on a $1 \times 1 \mathrm{~m}$ grid, subdivided into 50 x $50 \mathrm{~cm}$ subsquares, with $5 \mathrm{~cm}$ arbitrary horizontal levels. Sediments were dry screened with $2 \mathrm{~mm}$ mesh. Chipped stone and animal bone artifacts were sorted and bagged in the field. We did not pieceplot artifacts in situ because the test excavations were designed to expose site stratigraphy as completely as possible. Five combustion features were particularly well preserved in squares B5 and C5 (easternmost leg of the L-shaped Back Trench; see Fig. 3), and these were excavated and screened as separate features. Units were excavated to bedrock. Sections were drawn, photographed, and described in detail prior to backfilling.

Insert Figure 3 approximately here

Stratigraphy and site formation

The site stratigraphy exhibits two main components. Layer A is a grayish brown sandy silt, dominated by pulverized goat dung, which dates to the twentieth century. It includes redeposited EUP artifacts mixed together with late twentieth century artifacts, apparently discarded during recent use of the cave by shepherds and hunters. Layer A unconformably 
overlies Layer B, which is a variably consolidated brownish silt. Layer A is superficial across most of the Back Trench area, except where a twentieth century anthropogenic disturbance appears to have cut into Layer B in the SW portion of square B2 (Fig. 4). Layer A is $20-80 \mathrm{~cm}$ thick in the Front Trench (Fig. 5). This variation reflects infilling of what appears to be a recent shepherds' entrance ramp and building of a windbreak in the front chamber. Much of this has been infilled by silty pulverized goat dung mixed with redeposited Layer B material. Insert Figures 4, 5 approximately here

Layer B contains diagnostic EUP lithic artifacts throughout, but bone preservation and sediment phosphatization is variable. An apparent bone dissolution front (Weiner et al., 1993) runs roughly through the middle of the back trench, with no bone preserved in the intact stratified hearths in square B2. Hearths, lithic artifacts, and charcoal fragments are richly distributed throughout Layer B, independent of bone dissolution and phosphatization patterns. In the central portion of the Back Trench (the eastern half of squares B2, B3 and the western part of B4), bioturbation - from what appears to be a single large, infilled burrow-has more substantially mixed superficial recent shepherd material with EUP material. (A discarded foil food wrapper excavated at the bottom of the burrow deposits provides a maximum date of ca. 1980-1990 for the age of the bioturbation.) We have carefully separated subsquares and levels with Layer A deposits (containing redeposited flint and bone artifacts), bioturbated mixed deposits, and the in situ Layer B deposits.

Where they have survived intact, the Layer B deposits are rich in artifacts and stratified hearth features. Approximately $15-16 \mathrm{~m}^{2}$ of additional MHM Cave 2 surface between the Back and Front Trenches are estimated to preserve in situ Layer B deposits, but the thickness may vary from as little as $10 \mathrm{~cm}$ to over $70 \mathrm{~cm}$ (see Figs. 3-5). A roughly $4 \mathrm{~m}^{2}$ area of in situ Layer B 
sediment is protected under a slab of roof fall just north of square B2 in the Back Trench, preserving at least $110 \mathrm{~cm}$ of EUP deposits (see Fig. 3).

We have presented an earlier preliminary report on the 2010 test excavations (Stutz et al., 2012), including: initial field-lab assessment of the lithic assemblage (estimated to include ca. 20,000 flint artifacts, including cores, debitage, debris, and formal tools); the substantial macrofaunal assemblage (preliminary NISP count $=11,127$ ); the microfaunal assemblage; special finds, including fragments of burnished bone artifacts and a possible marine shell bead,

and abundant red and yellow ochre nodules; and a small number of isolated human teeth $(\mathrm{n}=2)$ and one human postcranial element (an atlas fragment). The post-cranial specimen is from unambiguous in situ Layer B context in square B5. New detailed taxonomic data for the microfaunal sample are given in Table 1.

The Mughr el-Hamamah lithic assemblage

The core reduction technology and tool typology from MHM Layer B can be assigned unambiguously to the early Upper Paleolithic sensu lato (ca. 50/45-30 ka). However, it is yet unclear whether the assemblage is best described as a variant of the Initial Upper Paleolithic/Emiran, the Early Ahmarian, or a third Levantine EUP industry or industrial facies that combines elements of the former. The latter possibility has been proposed by Davidzon and Goring-Morris (2003; see also Goring-Morris and Davidzon, 2006). The core technology features numerous blade and bladelet cores, many with characteristically long and narrow flakerelease surfaces (Fig. 6). Some blade striking platforms have been abraded and are covered with red ochre. Non-cortical blades and bladelets are not particularly common, but larger cortical blades are often modified into endscrapers (Fig. 7g-i). El-Wad points, backed knives, and burins are present but rare (Fig. 7j,k). No chanfrein endscrapers have been found (Bergman, 1988; 
Shea, 2013), but at least one chanfrein resharpening flake is present (Fig. 7e). However, the most chronologically diagnostic artifacts in the MHM assemblage are two points with thinned bases that resemble Emireh points (Fig. 7a-b). These finds support the possibility that MHM Layer B dates to the earlier millennia of the EUP period.

Insert Figures 6, 7 approximately here

Comprehensive techno-typological analysis is offering preliminary presence-absence data on the assemblage's technological features. More specifically, JJS's ongoing analysis highlights two main additions to the field observations made by AJS and LNS, reported in Stutz et al. (2012). The first is a strikingly high occurrence of scaled pieces, when compared with known Levantine EUP assemblages. JJS has recorded numerous scaled pieces or small bipolar cores (Fig. 61-m). Such artifacts are rare or under-reported from other EUP sites in the Levant (Shea, 2013). The second is confirmation that the assemblage recovered from in situ Layer B contexts is pristine (in that there is no evidence of rolling or redeposition) and free of Levantine Aurignacian, late Upper Paleolithic, Epipaleolithic or Neolithic diagnostic artifacts. None of the hallmarks of the later Levantine Aurignacian or Late Ahmarian (ca. 30-20 ka) technocomplexes, such as carinated pieces, twisted bladelets, or bladelets with Ouchtata retouch have been observed in the MHM assemblage (Coinman, 1993, 2000; Coinman and Henry, 1995; GoringMorris et al., 2009; Bar-Yosef and Belfer-Cohen, 2010; Shea, 2013). All lithic materials > ca. 1 $\mathrm{cm}$ were saved from the $2 \mathrm{~mm}$ screen, and AJS and LNS preliminarily sorted cores, debris, debitage, and formal tools from some of the mixed Layer A contexts, as well as a sample from in situ Layer B contexts. The mixing in Layer A involves EUP artifacts redeposited with later twentieth century materials and occasional undiagnostic pre-industrial ceramics. Where the EUP 
Layer B was recovered, all stratigraphic, chronometric, and lithic observations indicate a single in situ unmixed EUP assemblage.

\section{Materials}

During the test excavations inside MHM's main cave, 35 charcoal samples were collected from in situ Layer B EUP contexts that do not exhibit evidence of vertical mixing. These samples include charred botanical materials located within or directly under consolidated ash lenses associated with hearth features. Additional charcoal specimens were recovered underneath flat anthropogenic limestone slabs and a basalt cobble manuport. This latter artifact was wedged into a crevice in the cave wall, lying on top of a small remnant of characteristic brown compact Layer B sediment, roughly $30 \mathrm{~cm}$ above the nearby extant cave surface, where Layer B was eroding out in square B5 (Fig. 8). An el-Wad point was found in situ immediately underlying the cobble (see Fig. 7d). Thus, the charcoal adhering to the base of the cobble in depositional context (designated MHM-6) provides a minimum age for Layer B.

Insert Figure 8 approximately here

Previously, we obtained initial AMS ${ }^{14} \mathrm{C}$ ages from a portion of MHM-6 and three other samples (MHM-2, 4 and 5), which were all pretreated using the standard acid-base-acid (ABA) protocol (Stutz et al., 2012). The resulting ages, which ranged from ca. $43-30{ }^{14} \mathrm{C}$ ka, indicated that MHM Layer B accumulated during the onset of the EUP (see the Supplementary Online Material $[\mathrm{SOM}])$. However, several studies have shown that ABA pretreatment often yields dates on old (> 35-40 ka) charcoal that are too young, because of incomplete removal of small amounts of contamination (e.g., Bird et al., 1999). Moreover, for samples near the limit of ${ }^{14} \mathrm{C}$ detection, it is especially important to minimize contamination in the $\mathrm{CO}_{2}$ purification line, while also carefully calibrating background ${ }^{14} \mathrm{C}$ levels with frequent blank measurements (Pigati et al., 
2007). Thus, the remaining portions of these samples, as well as several others, were chosen for further AMS ${ }^{14} \mathrm{C}$ dating following ABOx-SC pretreatment, which has been shown to be more effective in removing secondary carbon species from charcoal (Bird et al., 1999; Pigati et al., 2007; Higham et al., 2009; Brock and Higham, 2011). Overall, MHM-2, 4, 5 and 7-11 span the best-preserved portions of the EUP Layer B-a roughly $50 \mathrm{~cm}$-deep slice of a stratigraphic unit that is lithologically coherent, consisting of stratified combustion features and a medium brown, often moderately consolidated and variably phosphatized matrix with silt, ash, and abundant charred wood fragment inclusions (Table 2).

Insert Table 2 approximately here

\section{Methods}

\section{ABOx-SC sample pretreatment for AMS radiocarbon dating}

We followed the protocols detailed in Bird et al. (1999), with the exceptions that base treatments were repeated as necessary and rinsing of the sample material between the base and wet oxidation steps was omitted. JSP and JW's experience in treating old charcoal samples has shown that significant sample material can be lost during that particular rinse step without any real benefit. For each sample, between 19 and $75 \mathrm{mg}$ of crushed charcoal was transferred to a 50 $\mathrm{ml}$ polypropylene centrifuge vial. The initial acid step, which removes unwanted carbonates, consisted of immersing the sample material in $30 \mathrm{ml}$ of $1 \mathrm{~N} \mathrm{HCl}$ at $60{ }^{\circ} \mathrm{C}$ until the reaction was visibly complete (minimum 30 minutes). The supernatant was discarded, the sample was rinsed in ultrapure (UHP; ASTM Type I, 18.2 M $\Omega$ ) water, and then treated with $30 \mathrm{ml}$ of $1 \mathrm{~N} \mathrm{NaOH}$ to remove humic acids and other base-soluble organic compounds. The base step was carried out at $60{ }^{\circ} \mathrm{C}$ for $\geq 1$ hour and was repeated until either the supernatant remained clear, indicating complete removal of unwanted contaminants, or six base washes were completed and the color 
of the supernatant was no longer changing. Finally, the sample material was immersed in $30 \mathrm{ml}$ of potassium dichromate solution $\left(0.1 \mathrm{M} \mathrm{K}_{2} \mathrm{Cr}_{2} \mathrm{O}_{7}\right.$ in $\left.2 \mathrm{M} \mathrm{H}_{2} \mathrm{SO}_{4}\right)$ for $14-24$ hours to concentrate oxidation-resistant elemental carbon (OREC). Upon completion, the supernatant was discarded and the OREC was rinsed repeatedly in UHP water at $60{ }^{\circ} \mathrm{C}$ until the rinse water was clear and the $\mathrm{pH}$ was between 4 and 7 . The sample was then dried using a heat block at $80{ }^{\circ} \mathrm{C}$.

All treated samples were combusted by a step-wise sequence of increasing temperatures: $200,325,625$, and sometimes $800{ }^{\circ} \mathrm{C}$. Prior to each temperature step, the combustion chamber was evacuated to pressures of less than $0.02 \mathrm{~Pa}$, filled with approximately $160 \mathrm{kPa}$ of $99.999 \%$ $\mathrm{O}_{2}$, and then the furnace temperature was raised to the specified value. The samples were initially heated to $200{ }^{\circ} \mathrm{C}$ for 15 minutes, after which all gases (including $\mathrm{CO}_{2}$ that was adhered to the sample surface) were discarded. The remaining material was then combusted at $325{ }^{\circ} \mathrm{C}$ for 15 minutes, and the resulting $\mathrm{CO}_{2}$ was collected, purified, measured, and reduced to graphite if the yield was greater than $100 \mu \mathrm{g} \mathrm{C}$. The sample material that survived the $325^{\circ} \mathrm{C}$ step was then combusted at $625^{\circ} \mathrm{C}$ for $30-60$ minutes. As before, all $\mathrm{CO}_{2}$ released at $625^{\circ} \mathrm{C}$ was collected, purified, measured, and reduced to graphite if the yield was greater than $100 \mu \mathrm{g} \mathrm{C}$. Finally, in cases in which the sample material was not obviously consumed by the lower-temperature steps, it was combusted at $800{ }^{\circ} \mathrm{C}$ for 30 minutes, and the resulting $\mathrm{CO}_{2}$ was collected, purified, measured, and then discarded. No sample yielded more than $2 \mu \mathrm{g} \mathrm{C}$ for the $800{ }^{\circ} \mathrm{C}$ combustion step.

There was one exception to these protocols. Sample MHM-6 (Aeon 1028) was too small (8.72 mg dry) for ABOx pretreatment, so the wet chemistry was limited to the standard ABA protocol. We followed the same combustion steps described above for this sample, and 
converted $\mathrm{CO}_{2}$ recovered from both the 325 and $625{ }^{\circ} \mathrm{C}$ fractions to graphite. However, only the graphite from the $625{ }^{\circ} \mathrm{C}$ fraction was submitted for ${ }^{14} \mathrm{C}$ AMS measurement.

\section{Radiocarbon calibration methods}

The radiocarbon dates were calibrated following Ramsey (2001). The measured ${ }^{14} \mathrm{C}$ age is designated $r_{m}$, the associated standard error estimate $\sigma_{m}$, and the theoretical calibration curve is a continuous function of time, $r(t)$. The current standard estimate of $r(t)$ for atmospheric Northern Hemisphere organic samples is the INTCAL13 calibration curve, and it extends close to the technical limits of radiocarbon dating, 50,000 cal BP (Niu, 2013; Ramsey, 2013; Reimer et al., 2013; Staff, 2013). A second $r(t)$ estimate is the CalPal-Hulu 2007 curve, which includes much of the radiometric data included in the INTCAL13 curve, using simple cubic spline interpolation between radiometric data points throughout its length (Weninger and Jöris, 2008). We used the CalPal-Hulu 2007 curve to extend our calibration dataset from 50,001 to 59,500 cal BP. Until the next revision of the INTCAL Northern Hemisphere calibration curve is published — potentially extending the maximum age of the dataset beyond 50,000 cal BP—our approach minimizes any possible 'left-censoring' effects, which can begin to influence calibration of ${ }^{14} \mathrm{C}$ dates approaching $45{ }^{14} \mathrm{C}$ ka BP.

All estimations of $r(t)$ involve a standard error function $\sigma(t)$. Given the available calibration data on which $r(t)$ is constructed, the probability that a sample $m$ has age $t$ is estimated based on the following proportion expression (Ramsey, 2001):

$$
p(t) \propto \frac{\exp \left[-\left(r_{m}-r(t)\right)^{2} / 2\left(\sigma_{m}^{2}+\sigma^{2}(t)\right)\right]}{\sqrt{\sigma_{m}^{2}+\sigma^{2}(t)}}
$$

Because calibration $r(t)$ and $\sigma(t)$ values are measured and estimated across calendrical time intervals that vary from decadal to semi-millennial, we determined natural cubic spline functions across the calibration datasets and calculated $r(t)$ and $\sigma(t)$ values for each yearly interval, from 0 
cal BP to 59,500 cal BP. For each sample, $m$, and each yearly interval $t$ between $0-59,500 \mathrm{cal}$ BP we then calculated the relative probability that $r(m)$ corresponds to $t$. Finally, we standardized the relative probabilities for each yearly interval, so the total area under the curve $p_{m}(t)$ from $0-$ 59,500 cal BP is 1. All calculations were made in Microsoft Excel (version MSOffice 2011 for Macintosh), and the cubic spline functions and solutions were determined with the open-source Excel user-defined function CSpline (Jenkins, 2009). The resulting annually resolved calibration spreadsheet is provided as SOM.

For each age reported in this study, we calculated summary statistics for the calibration probability distributions: the median and the upper and lower bounds of the central $68.2 \%$ and 95.4\%, respectively, of the estimated area under the curve. We calculated the same descriptive statistics for the summed probability distribution for the nine AMS dates on eight ABOx-SCpretreated charcoal samples, along with the individual date on the humic acids extracted from MHM-10 (Aeon 1038) and the date on the ABA-pretreated MHM-6 specimen (Aeon 1028).

\section{Results}

$A B O x-S C$ and $A M S{ }^{14} C$ Measurement Results

All pretreated charcoal samples yielded significant quantities of $\mathrm{CO}_{2}$, and all AMS-dated $\mathrm{CO}_{2}$ fractions exhibited significant but small ${ }^{14} \mathrm{C}$ levels, providing a suite of 11 radiocarbon ages on nine specimens (Table 3). Eight of the MHM specimens were subjected to ABOx-SC pretreatment and exhibited little mass loss from the chemical wash and wet oxidation steps, indicative of excellent preservation of the charcoal (Fig. 9; see Table 3). The $\mathrm{CO}_{2}$ yields following combustion of these specimens fell in the 50-56\% range, which is well within the $\mathrm{CO}_{2}$-level variation when fresh charcoal is combusted at ca. $400-600{ }^{\circ} \mathrm{C}$ (Rebollo et al., 2008, 2011). As noted above, a ninth MHM specimen (MHM-6) was pretreated by ABA methods. 
Insert Figure 9, Table 3 approximately here

The ${ }^{14} \mathrm{C}$ activities of the samples treated by ABOx-SC methods ranged from $0.0071 \pm 0.0009$ (MHM-5) to $0.0113 \pm 0.0012$ (MHM-7); the activity of the sample (MHM-6) treated by ABA was slightly higher, $0.0147 \pm 0.0013$; and the humic acids recovered from MHM10 yielded a ${ }^{14} \mathrm{C}$ activity of $0.0097 \pm 0.0010$, well within the range exhibited by the $\mathrm{ABOx}-\mathrm{SC}$ samples. All of these values are significantly higher than blank or background levels at the time of processing the samples and therefore warrant the calculation of ${ }^{14} \mathrm{C}$ ages.

Calculated ${ }^{14} \mathrm{C}$ ages for the suite of $\mathrm{ABOx}-\mathrm{SC}$ treated MHM samples range from $39.7 \pm 1.1$ to $36.01 \pm 0.66{ }^{14} \mathrm{C}$ ka, the ABA-treated sample (MHM-6) yielded a ${ }^{14} \mathrm{C}$ age of $33.89 \pm 0.72{ }^{14} \mathrm{C}$ ka, and the humic acids (MHM-10) dated to $37.21 \pm 0.79{ }^{14} \mathrm{C}$ ka (see Table 3). Although the uncertainties are relatively similar to many reported ${ }^{14} \mathrm{C}$ ages in the $35-40{ }^{14} \mathrm{C}$ ka range, they are, in fact, conservative. They incorporate all of the standard relevant uncertainties and account for unknown sources of error using a 'total error multiplier' (TEM). The TEM, sometimes called a 'laboratory error multiplier', is produced by statistically analyzing the results of many measurements on reference materials (i.e., samples of known activity). Because it is based on total error without regard to cause, the TEM accounts for virtually all sources of error, even those of unknown origin. It is constructed to produce the condition that approximately $68 \%$ of results on knowns fall within one sigma of the expected value, 95\% fall within two sigma, and so on. In effect, multiplying the original measurement uncertainty by the TEM mathematically coerces quoted uncertainties to have their standard implied meaning.

A key question is "should these ages be viewed as accurate ages or as minimum ages?" The primary issue at hand is the disproportionate effect that small amounts of young contamination can have on old samples (see Pigati et al. [2007] for discussion). We cannot 
entirely discount the possibility that extremely small amounts of young contamination made it through the ABOx-SC treatment and remained in the pool of carbon atoms that was converted to graphite and analyzed by AMS. The ABOx-SC treatment has been shown to remove significant quantities of contamination, but it is not certain that the treatment protocol effectively removes exactly all of the contamination present. Thus, like ABA-derived ages that are $>35 \mathrm{ka}$ or so, ages in the same time range derived from the $\mathrm{ABOx}-\mathrm{SC}$ technique should be viewed as minimum ages unless there is independent evidence to suggest otherwise.

In the case of the MHM ages, the question then becomes, "are the ages finite or infinite?" In other words, are the reported ages close to the true age or are the samples infinitely-aged (> 50 ka) but contaminated? In our view, the ABOx-SC ages probably underestimate the true ages of the samples by only a small amount, maybe on the order of a few hundred to a couple of thousand years, and are unlikely to be infinitely-aged. This conclusion is based on observations of several factors, including the behavior of the samples during processing, the coherency of the suite of $\mathrm{ABOx}-\mathrm{SC}$ ages in Layer $\mathrm{B}$, the agreement between the ABOx-SC ages and the humic acid age (MHM-10), and the fact that the ABOx-SC ages were only slightly older than the ABAderived age (MHM-6).

In particular, the coherence of the nine ABOx-SC dates-including two AMS dates on the $325^{\circ} \mathrm{C}$ and $625^{\circ} \mathrm{C}$ heating-step fractions for sample MHM-5-is consistent with the associations of the large charcoal fragments with combustion features and horizontally oriented anthropogenic stone artifacts, all situated within a lithologically coherent Layer B context. This coherence includes the associated lithic assemblage sample, initial sorting of which has documented no intrusive technologically or typologically diagnostic artifacts from later time periods. We note that MHM-6 (Aeon 1028) exhibited evidence of excellent wood charcoal 
preservation. However, a portion of the specimen had been used for preliminary (ABApretreated) ${ }^{14}$ C AMS dating (see SOM; Stutz et al., 2012), and the remaining material from MHM-6 was judged too small a priori to risk subjecting it to ABOx pretreatment. The ABApretreated material from MHM- 6 yielded $56 \% \mathrm{CO}_{2}$, released during the combustion step at 625 ${ }^{\circ} \mathrm{C}$, typical of intact hardwood charcoal (Rebollo et al., 2008). The slightly younger age of the resulting assay Aeon 1028 (33.89 $\left.\pm 0.72{ }^{14} \mathrm{C} \mathrm{ka} \mathrm{BP}\right)$ is consistent with the sample's stratigraphic position, providing a conservative minimum limiting age for the end of Layer B (Fig. 10; see Table 2).

Insert Figure 10 approximately here Radiocarbon Calibration Results

The calibrated median and $95.4 \%$ confidence interval ages are listed for each radiocarbon date produced in this study (Table 4). From the available INTCAL13 and CalPal calibration data (Weninger and Jöris, 2008; Reimer et al., 2013), the summed probability distribution of the Mughr el-Hamamah ABOx-SC AMS dates (excluding the ABA-pretreated date on MHM-6 and the date on the MHM-10 humic acids) reliably estimates the span within which the bulk of the in situ EUP Layer B accumulated (Fig. 10). The central 95.4\% of the ABOx-SC summed distribution spans 44.6-39.3 ka. The minimum limiting age on MHM-6 yields a 95.4\% probability range of 39.9-36.4 ka. Insert Table 4 approximately here

The summed probability distribution is a relevant, conservative source of information about occupation span. This summary distribution is preferred when a sample of $n{ }^{14} \mathrm{C}$ dates on otherwise well-preserved organic material is associated with insufficient prior information to resolve the order of those dates chronologically, either due to complexity of the stratigraphy or 
standard error in the ${ }^{14} \mathrm{C}$ measurement (Weninger et al., 2011). In MHM Layer B, bioturbation in the center of the back trench has made it impossible to trace microstratigraphy between squares B5-C5 and B2, although future excavation may solve this problem. In addition, given the prior expectation of EUP age (ca. 50-30 ka), it is essentially impossible to rule out that small pieces of charred botanical material from different occupation episodes within Layer B have been mixed with the large, apparently intact charcoal specimens, adding an unknown but significant level of chronometric error for individual radiocarbon dates (cf. Zilhão, 2013). It is generally unknownfor any of the charcoal samples_-whether the given specimen's measured age has been influenced by trace amounts of younger organics, older clay and organics, in situ chemical diagenesis, trace laboratory contamination from younger samples, or trace contamination from geologically ancient laboratory blanks. Given the small amounts of radiocarbon remaining after seven to eight half-lives, there is simply insufficient prior information to determine whether a stratigraphically detailed conditional model would actually yield an accurate posterior probability distribution, whatever the increase in precision. The summed probability distribution is conservative because it is the distribution of statistical likelihoods that any of the $n{ }^{14} \mathrm{C}$ dates corresponds to calendar age $t$.

The central $95.4 \%$ of the area of the summed calibration distribution thus provides a standardized calendrical age confidence interval within which all of the $n$ dates likely fall. The summed probability distribution's modal value between 41-42 ka cal BP provides the best available, conservative minimum-age estimate of peak human occupational intensity. In light of the argument above concerning the disproportionate impact of trace young contamination, the maximum point on the $95.4 \% \mathrm{CI}(44.6 \mathrm{ka})$ provides a reasonable maximum limiting age for peak occupational intensity. Given the radiocarbon measurement and calibration error, the actual 
duration of occupation or identification of periods of site abandonment cannot currently be determined.

The coherence of the eleven AMS dates-including the humic acid and ABA-pretreated charcoal dates - also support other useful probabilistic estimates. The joint probability distribution for the outcome that every radiocarbon assay, $r_{i}$, is actually older than calendrical minimum limiting age $T_{t a q}$ is presented in the SOM. Based on all AMS ${ }^{14} \mathrm{C}$ ages reported in this study-including the ABA-pretreated assay on MHM 6- the $T_{\text {taq }}$ value at which $\mathrm{P}\left(t_{i \ldots n}>T_{t a q}\right)=0.99$ is $36 \mathrm{ka}$ cal BP. The $T_{t a q}$ value at which $\mathrm{P}\left(t_{i \ldots n}>T_{t a q}\right)=0.01$ is $40 \mathrm{ka} \mathrm{cal} \mathrm{BP}$. It is clearly unlikely that the measured ${ }^{14} \mathrm{C}$ activity reflects an occupational history in which the minimum limiting age $T_{t a q} \geq 40 \mathrm{ka}$. However, the probability that just one radiocarbon date, $r_{i}$, has a calendar age $t_{i}>T$ provides a conservative evaluation of the oldest calendar date in the Layer B sample. The central $95.4 \%$ of the distribution of $P\left(t_{i}>T\right.$ and $\left.t_{j \neq i} \leq T\right)$, which corresponds

to the oldest anthropogenic activity measured for MHM Layer B, falls between 45.1 and 42.4 ka, with a median value of $43.7 \mathrm{ka}(\mathrm{SOM})$.

\section{Discussion}

The results presented in this study provide a new accuracy benchmark for dating an EUP context in a Mediterranean region cave site, where in situ charcoal associated with anthropogenic combustion features provides the most reliable material for measuring the chronometric age of the associated deposits (Rebollo et al., 2008, 2011; Higham et al., 2009; Brock and Higham, 2011). The new ABOx-SC AMS ${ }^{14} \mathrm{C}$ dates from MHM Layer B confirm that, in the millennia prior to $40 \mathrm{ka}$, Levantine human groups had shifted technological strategies for removing elongated flint blanks from cores, frequently making and using endscrapers and burins, while 
they maintained occasional use of Levallois techniques, which had dominated earlier Middle Paleolithic stone tool production.

The MHM results are generally consistent with ABOx-pretreated charcoal radiocarbon dates from other Levantine EUP sites. For example, using the calibration method and data described above, three ABOx-pretreated charcoal assays from Üçağızlı Cave's lowermost stratigraphic unit, Layer I, yield a summed calibration distribution, the $95 \%$ confidence interval of which is 44.1-37.7 ka cal BP (Table 5; Kuhn et al., 2009). This layer defines the base of the sequence associated with Initial Upper Paleolithic (IUP) assemblages, which in turn underlies a sequence of Early Ahmarian lithic assemblages (Kuhn et al., 2009; Kuhn and Zwyns, 2014). Insert Table 5 approximately here

The more extensive set of ABOx-pretreated AMS dates from Kebara Cave includes in situ LMP and EUP charcoal samples. The Kebara results raise the possibility that the southern Levantine MP-UP transition may have begun somewhat earlier, ca. 47 ka (Rebollo et al., 2011). Kebara is currently the best-dated LMP-EUP stratified sequence in the Levant. However, it is clear the Kebara charcoal specimens underwent more variable and sometimes more extensive chemical diagenesis than did the Mughr el-Hamamah specimens (see Fig. 9). If a recent reanalysis of the Kebara stratigraphy is correct, then the unconformity between the LMP Unit V and the Early Ahmarian Units IV-III may have lasted millennia, with many of the EUPassociated charcoal ${ }^{14} \mathrm{C}$ dates impacted by redeposited LMP material (Zilhão, 2013; Bar-Yosef, Personal communication, 2014). In light of such uncertainty, we emphasize that the nine tightly statistically clustered ABOx-SC AMS dates from MHM Layer B-obtained on consistently well-preserved charcoal—establish a reliable, conservative minimum age for EUP onset in the 
southern Levant. This value may be estimated at $42 \mathrm{ka}$, which is the younger end of the $95.4 \%$ confidence interval for the oldest measured activity in MHM Layer B, ca. 45-42 ka.

\section{Insights from stepped combustion}

It is unclear why all but one of the MHM ABOx-pretreated samples completely combusted at the relatively low laboratory temperature step of $325^{\circ} \mathrm{C}$. It is unlikely that this is due to chemical diagenesis, as the mass-loss and $\mathrm{CO}_{2}$-yield data are indicative of well-preserved charred organic material. It is more likely that the stepped-combustion results reflect some combination of the following factors: the wood fuel source, its state prior to incorporation into a prehistoric burning feature, and the temperature and oxygen levels in the prehistoric combustion installations. Field observations at MHM document an unusually high density of macroscopic charred botanical fragments and patches, with some specimens as large as $3 \mathrm{~cm}$ (see Fig. 4). The charred botanical material is abundant inside and outside of hearths, although ash (the result of oxidizing vegetation tissue at high heat) is not as extensively distributed outside of discrete hearth lenses, as has been observed at other LMP and EUP cave sites (Goldberg et al., 2009; Weiner, 2009). This spatial distribution raises the hypothesis that prehistoric combustion technology at MHM sometimes went beyond tending simple campfires, involving the restriction of oxygen availability_-perhaps for the purpose of smoking food.

Insights from the Mughr el-Hamamah chronology in Levantine regional context

Table 5 summarizes key Levantine EUP archaeological sequences, associated industries, and — where available—relatively high-quality chronometric data. We adopt stringent, conservative criteria for presenting actual chronometric values. We present closed age ranges (ka cal BP) only when ABOx-pretreated ${ }^{14} \mathrm{C}$ dates or independent TL dates are available. Of course, even these should continue to be taken with caution; they are simply the best available estimates, 
to be used for refining research questions into the MP-UP transition's chronology. We acknowledge that the relevance of all high-quality AMS dates on ABOx-SC pretreated charcoal still depends on sample preservation. Just as critically, it depends on a sufficient understanding of that sample's context in its site formation history (Zilhão, 2013).

From this perspective, we have treated cautiously the recently published radiocarbon dates on marine shell from Ksar Akil Rockshelter (see Douka et al., 2013). The two shell artifacts stratigraphically associated with Ksar Akil LMP layer XXVIII have suffered 100\% post mortem replacement of the biogenic aragonite mineral with calcite. Their radiocarbon ages are thus minimum estimates of their true ages. When compared to thermoluminescence, electron spin resonance, and $\mathrm{ABOx}{ }^{14} \mathrm{C}$ dates from Amud and Kebara Cave LMP contexts, the Ksar Akil layer XXVIII shell dates may be considered to be surprisingly young. From the two LMPassociated shells, the best-preserved calcitic (i.e., recrystallized or adsorbed) material yielded the date OxA-20491 (Douka et al., 2013), exhibiting an INTCAL13 age of 43.7-42.6 ka (95.4\% CI, calculated according to the methods in this article). Radiocarbon, TL and ESR dates from other Levantine LMP and EUP sites have supported the view that the MP-UP transition unfolded significantly closer to ca. 45 or 50 ka (Valladas et al., 1987, 1999; Schwarcz et al., 1989; BarYosef et al., 1996; Bar-Yosef, 2000; Rink et al., 2001; Marks, 2003; Rebollo et al., 2011). In comparison, ten new dates on intact (100\%) aragonite mineral from shell artifacts associated variously with IUP, Early Ahmarian, and Levantine Aurignacian Layers XXII-IX at Ksar Akil (Douka et al., 2013) tightly cluster between 41.9-37.2 ka cal BP (summed calibration distribution, $95.4 \% \mathrm{CI}$, calculated according to the methods in this article). These ten dates show a slope very close to (and statistically indistinguishable from) zero, in the correlation between stratigraphic order and chronometric age (SOM). An eleventh Ksar Akil date on 100\% shell 
aragonite from the Levantine Aurignacian layer VIII does show good agreement with a stratigraphically associated, re-analyzed ABOx-pretreated charcoal assay, yielding an INTCAL13 calibrated age of ca. 34-33 ka for the middle of the Levantine Aurignacian deposits at this important site (see Douka et al., 2013). These Levantine Aurignacian-associated chronometric data are in agreement with a range of ABA-pretreated charcoal dates on material associated with Levantine Aurignacian occupations throughout the southern Levant (GoringMorris and Belfer-Cohen, 2003; Lengyel et al., 2006). (It is important to note that, although ABOx-SC pretreatment more aggressively and consistently removes contaminants from charcoal, trace contaminants have a geometrically decreasing effect on samples one or more halflives younger than those from ca. 40 ka contexts; cf. Zilhão, 2013.) The new Ksar Akil data (Douka et al., 2013) are best explained by chemical diagenesis on the LMP-associated samples and a demonstrated, substantial 'old shell effect,' in which later Early Ahmarian and Levantine Aurignacian occupants gathered Mediterranean shells from organisms that lived mainly during IUP or the beginning of the Early Ahmarian occupation periods (Douka, 2011).

In preparing Table 5 we carefully used the chronometric data from the ten Ksar Akil $100 \%$ aragonite dates as follows. We noted that the ten $100 \%$ aragonite dates span the IUP Layer XXII to the Levantine Aurignacian Layer IX. Eight of those dates are recorded—based on documentation from the original excavations—as associated with Early Ahmarian layers (Douka et al., 2013). We cautiously infer that the older bound of the $95.4 \%$ confidence interval for the summed calibration distribution of the ten aragonite samples must have fallen within the IUP occupation of Ksar Akil. We thus note that available chronometric data indicate the IUP as beginning before $41.9 \mathrm{ka}$ cal BP and ending at some time later. We note that the minimum age of IUP onset is nearly identical to the minimum age of the oldest recorded anthropogenic activity in 
MHM Layer B, ca. 42 ka. As discussed above, the MP-associated shell dates from Ksar Akil were obtained on diagenetic calcite and are surprisingly young. Thus, the oldest IUP layers (XXVI-XXV) may actually be several millennia older than argued in Douka et al. (2013), putting the Ksar Akil sequence chronologically more in line with the recent EUP-associated ABOxtreated charcoal data from Kebara, Üçağızlı, and Mughr el-Hamamah, along with the suggestive early date for Boker Tachtit Level 1. Currently, there is no evidence to warrant rejecting the general chronological framework, in which the MP-UP technological transition occurs around or before $45 \mathrm{ka}$ in the Levant (Bar-Yosef and Belfer-Cohen, 2010; Rebollo et al., 2011; Hovers and Belfer-Cohen, 2013). The challenge remains, however, to sample new, carefully provenienced and selected charcoal, U-Th, TL, and optically stimulated luminescence (OSL) specimens that are tightly associated with the human activity we seek to date-studying these materials with measurement and calibration methods that yield greater precision without risking accuracy.

It is also noted that, because the Ksar Akil chronometric data involve a shell associated with Layer XXII, the famous AMH specimen Egbert, associated with overlying Early Ahmarian Layer XVII or XVIII (Bergman and Stringer, 1989), must post-date ca. $42 \mathrm{ka}$. However, possible old-shell effects prevent assigning a more precise minimum limiting age for the Egbert burial than the overlying Levantine Aurigancian ABOx charcoal date of ca. 34 ka. If the stratigraphic attribution of the AMH adult maxilla fragment to Layer XXV is correct (Douka et al., 2013), then that specimen certainly pre-dates ca. $42 \mathrm{ka}$ (see Table 4).

Lithic technological variability in the Levant, ca. 45-30 ka

The chronological and geographic distributions of lithic industries from the LMP and EUP periods in the Levant are now generally well documented, spanning ca. 75-30 ka (MIS 43). It is well established that LMP Levantine assemblages tend to be dominated by 
unidirectional-convergent Levallois core-reduction techniques, with very few formal tools besides Levallois points, although LMP open-air sites exhibit more variation in Levallois and expedient core reduction strategies (Ahmad and Shea, 2009; Hovers et al., 2009; Shea, 2013). There are well-defined stratigraphic sequences spanning the MP-UP Transition at Ksar Akil Rockshelter and Kebara Cave (Bergman and Stringer, 1989; Bar-Yosef et al., 1996; Rebollo et al., 2011; Douka et al., 2013;). Although there is likely a significant gap between the LMP and EUP occupations at the open-air Umm el-Tlel site in Syria, it also exhibits a substantial stratified EUP sequence (Ploux and Soriano, 2003). There are numerous partial sequences at other sites in the Levant (Goring-Morris and Belfer-Cohen, 2003; Bar-Yosef and Belfer-Cohen, 2010; Shea, 2013). Across the region, the EUP often follows the industry sequence Initial Upper Paleolithic (IUP)-Early Ahmarian-Levantine Aurignacian, roughly spanning the 50/45-30 ka time frame (Goring-Morris et al., 2009; Bar-Yosef and Belfer-Cohen, 2010; Shea, 2013).

This sequence has been confirmed most recently by Hershkovitz et al. (2015), who expand on preliminary reports for Manot Cave, in the western Galilee, Israel (Barzilai et al., 2012; Marder et al., 2013). They describe an in situ stratigraphic sequence, including what appears to be an ephemeral IUP-associated deposit, overlain by well-defined, rich Early Ahmarian and Levantine Aurignacian occupational layers. Through careful application of isochron analysis and light-stable isotope wiggle-matching to more detailed speleothem sequences, Hershkovitz et al. (2015) obtain uranium-thorium series (U-Th) dates on EUPassociated flowstones. These results generally confirm the Levantine lithic industry chronology suggested by the high-resolution data, summarized in Table 5. In particular, the Manot Levantine Aurignacian occupation dates to ca. $30 \mathrm{ka}$, and a flowstone underlying the lowermost Early Ahmarian deposits dates to $43-41 \mathrm{ka}$. This latter result accurately corresponds with the estimate 
for the transition from the IUP to the Early Ahmarian at Ksar Akil, as discussed above. (We note that the U-Th dates on a calcitic crust adhering to an anatomically modern human skullcap found in an otherwise non-archaeological portion of the cave are certainly interesting. The average of the $11 \mathrm{U}-\mathrm{Th}$ dates raises the distinct possibility that anatomically modern humans were present in the Levant some time between 60-50 ka. However, the U-Th dates exhibit a wide spread, with each date exhibiting a coefficient of variation $>9 \%$ [the maximum CV $=27 \%$ ]. As Hershkovitz et al. [2015] acknowledge, the calcitic crust formed after the human remains were deposited. It is difficult to rule out that the skull is in fact older than ca. 65/70 ka. Yet, it may be as young as ca. $40 \mathrm{ka})$.

The IUP is the name now most widely used for a series of lithic, bone tool, and bead assemblages, particularly marked by lithic cores with Levallois-like lateral preparation and platform faceting (Kuhn and Zwyns, 2014). However, the IUP technique is used to produce a convex core surface for recurrent unidirectional or bidirectional blade removal (Marks, 2003; Brantingham et al., 2004; Kuhn et al., 2009; Tostevin, 2012). Meignen (2012) has underscored that during reduction, IUP knappers exploited the lateral portions of the cores for blade removals, representing a strategic shift from a Levallois surface-maintenance approach for elongated blank production to a volumetric one. Although scholars increasingly prefer the term IUP, this industry is still frequently labeled the Emiran or Emirian (Bar-Yosef and Belfer-Cohen, 2010; Shea, 2013; cf. Garrod, 1951, 1955). Diagnostic IUP/Emiran flint tools include Emireh points and chamfered pieces (best documented at Ksar Akil and other sites in Lebanon), burins on truncations, and endscrapers (Ohnuma and Bergman, 1990; Copeland, 2000; Kuhn et al., 2009; Meignen, 2012; Shea, 2013). Tostevin (2012) has demonstrated a remarkable similarity in technology between Levantine IUP core reduction strategies and those of the roughly 
contemporaneous EUP Bohunician industry in Central Europe, which may actually date to ca. 50-45 ka (Richter et al., 2009).

In comparison, the 'classic' Levantine Early Ahmarian industry has been noted for its similarity to Proto-Aurignacian assemblages elsewhere in western Eurasia, the bulk of which appear to date to ca. 40-35 ka in Western Europe (Mellars, 2006; see Banks et al., 2013a, b; Higham et al., 2013). These assemblages exhibit more standardized, narrow blade blanks, often retouched into el-Wad/Font-Ives points (Davidzon and Goring-Morris, 2003; Goring-Morris and Davidzon, 2006; Bar-Yosef and Belfer-Cohen, 2010; Shea, 2013). Distinctive retouched Dufour bladelets, with inverse retouch of the Dufour subtype, also appear in Early Ahmarian/ProtoAurignacian assemblages (Monigal, 2003).

Finally, the Levantine Aurignacian is an industry dominated by flake production but also includes characteristic carinated scraper/cores and twisted bladelet debitage (Goring-Morris and Belfer-Cohen, 2006; Williams and Bergman, 2010). Levantine Aurignacian assemblages also include diverse antler and bone points, shell beads, and animal-tooth pendants (Bar-Yosef and Belfer-Cohen, 2010; Williams and Bergman, 2010; Shea, 2013). Levantine Aurignacian assemblages are always found overlying Early Ahmarian layers at sites where both industries are present: Ksar Akil Rockshelter, Kebara Cave, el-Wad Cave, Raqefet Cave, and Manot Cave (Bergman, 1988; Bergman and Stringer, 1989; Lengyel et al., 2006; Goring-Morris et al., 2009; Bar-Yosef and Belfer-Cohen, 2010; Barzilai et al., 2012; Marder et al., 2013; Hershkovitz et al., 2015). However, chronometric data from ABA-pretreated conventional and AMS dates on charcoal, along with some TL and U-Th dates, have not yielded clear resolution on the absolute chronology of these industries. The ABA-pretreated AMS dates, which are less likely to be affected by contamination in the 5-6 half-life age range, suggest that a later cluster of Early 
Ahmarian sites may have been at least partially contemporaneous with Levantine Aurignacian assemblages, although it is uncertain when in the 40-30 ka timeframe this contemporaneity may have occurred (Coinman, 2000, 2002; Goring-Morris and Belfer-Cohen, 2003; Kadowaki, 2013). Insights into lithic technological variability in the earliest Upper Paleolithic, ca. 45-40 ka Building on the prescient observations by Davizdon and Goring-Morris (2003; GoringMorris and Davidzon, 2006), we suggest that the IUP/Emiran as currently defined does not encompass the technological variability that existed during Levantine EUP emergence, $>40 \mathrm{ka}$. The ABOx data suggest substantial temporal overlap among the earliest EUP occupations at Üçağızlı, Kebara, and MHM > 40 ka. Recent U-Th results are also consistent with temporal overlap with the Manot Cave IUP occupation, along with by the onset of the Early Ahmarian, ca. 42 ka (Hershkovitz et al., 2015). The lowermost EUP layers at Boker Tachtit, Ksar Akil, and Üçağızlı are unambiguously associated with Initial Upper Paleolithic/Emiran assemblages. In light of this fact, it is significant that neither Kebara Units IV-III nor MHM Layer B are dominated by IUP/Emiran technological features, yet incorporate rare or occasional diagnostic types (Bar-Yosef et al., 1996). In fact, such a pattern, involving what were described as Upper Paleolithic blade cores with Emireh points, was first discussed by Garrod (1951). However, from old excavations at el-Wad, Qafzeh, and Emireh Caves, it remains unclear to what extent postdepositional mixing caused these associations (Bar-Yosef and Vandermeersch, 1972). The technological features observed as present throughout the MHM Layer B deposit—occasional Levallois unidirectional convergent flakes, some with basal Emireh-point-like modification; blades and bladelets produced from prismatic cores (and, to be sure, possibly exhausted IUP cores that had become amorphous flake cores when discarded); and a surprisingly large number of bipolar cores/scaled pieces — constitute provisional evidence for the association of Early 
Ahmarian core-reduction strategies (cf. Goring-Morris and Davidzon, 2006) with at least some diagnostic IUP tool types and some previously unobserved patterns of technological variation in the ca. $45-40$ ka timeframe.

With analysis of the MHM assemblage ongoing, it must be emphasized that there are likely differences in technology and tool typological diversity between that site and Kebara Cave Units IV-III (Bar-Yosef, Personal communication, 2014). In addition, we note that Tor Fawaz rockshelter, in southern Jordan, preserved an archaeological layer containing an EUP assemblage that—like Kebara Units IV and III and Mughr el-Hamamah Layer B—is best classified as belonging to the Early Ahmarian industry, but with fewer and less standardized blade blanks and el-Wad points, more variable core-reduction strategies, and a small but significant amount of Levallois debitage (Kerry and Henry, 2003; cf. Davidzon and Goring-Morris, 2003). The archaeological layer overlies a regionally distributed dated loess horizon from ca. 45 ka (Henry, 1995; Kerry and Henry, 2003). Finally, the 'indeterminate early Upper Paleolithic' Layer IV assemblage underlying the Levantine Aurignacian at Raqefet Cave may also fit into this variable EUP phenomenon (Lengyel et al., 2006), restricted to the Mediterranean vegetation zone and Rift Valley basin of the southern Levant.

Bar-Yosef and Belfer-Cohen (2010) have recently suggested that the micromorphologically documented unconformity separating the LMP and EUP occupations of Kebara Cave (the contact between LMP Unit V and EUP Unit IV) may explain what would be a missing, very early and brief IUP/Emiran occupation in its transitional Middle-Upper Paleolithic sequence (see also Bar-Yosef et al., 1992, 1996; Bar-Yosef and Meignen, 2007; Zilhão, 2013). There is substantial uncertainty in the conventional ${ }^{14} \mathrm{C}$ dates from Boker Tachtit Level 1 (IUP/Emiran) (Marks, 1977a,b, 1983, 2003; Kuhn et al., 2009). The only other intact buried 
IUP/Emiran site in the southern Levant-Tor Sadaf, southern Jordan, with an overlying in situ Early Ahmarian layer-lacks chronometric measurements, although paleoclimatic evidence for relatively arid conditions is consistent with occupation contemporaneous with Lake Lisan's lowest Oxygen Isotope Stage 3 levels, ca. 48-40 ka (Fox and Coinman, 2004; Lisker et al., 2009).

It is possible that the IUP/Emiran-Early Ahmarian transition occurred earlier in the southern Levantine Mediterranean vegetation zone than it did elsewhere in the Levant; it may only be poorly documented in this area due to vagaries of preservation and survey coverage (cf. Hershkovitz et al., 2015). However, the rough penecontemporaneity of Kebara Cave Units IV and III, MHM Layer B, Üçağızlı Layer I, and Ksar Akil Unit XXII also preliminarily suggests something else. It is also possible that ca. $45 \mathrm{ka}$, the MP-UP Transition involved an intra-regional heterogeneous technological shift, with IUP technologies primarily utilized in the northern Levant and semi-arid margins, while substantially more variable core reduction and tool technologies were contemporaneously used in the southern Levantine Mediterranean phytogeographic zone and the Rift Valley (Jordan Valley and Wadi Arava). This possibility is consistent with a behavioral ecological model, in which IUP-style hard-hammer core reductionyielding thicker pointed or elongated blanks_-provided a marginal advantage for provisioning highly mobile groups, whereas more frequent prismatic blade and bladelet production provisioned longer residential camp stays, with more regular daily or logistical foraging trips from and back to those camps (cf. Kuhn, 1991, 1992; Stiner and Kuhn, 1992; Kuhn and Stiner, 2006).

Some recent suggestions about the geographic expansion of anatomically modern humans have focused on the possibility that the EUP in the Levant was initially marginal, at least until 
the emergence of classic Early Ahmarian technology, ca. 40 ka (Douka et al., 2013; Zilhão, 2013). However, it may be important to consider alternative hypotheses, involving interaction effects between ecological zones within the Levant, as we seek to understand how this region fit into a broader pattern of population expansion out of sub-Saharan Africa or southern Arabia. If Upper Paleolithic adaptations involved marginal but significant reductions in mobility, based on increases in gendered division of foraging and task labor (Kuhn and Stiner, 2006), the southern Levantine Mediterranean zone-with its higher ecological productivity and warmer winter temperatures at lower elevations-would have favored anatomically modern body proportions over Neandertal ones (Froehle et al., 2013; Stutz, 2014). The chronological and preliminary lithic results from MHM warrant further investigation of the interrelated, multi-scalar dynamics among African/southern Arabian dispersal into the Levant; population change and growth within the Levant; and dispersal from the Levant into the rest of western Eurasia (cf. Kuhn, 2013; Stutz, 2014).

\section{Conclusion}

The new ABOx-SC AMS ${ }^{14} \mathrm{C}$ ages and observations on the associated lithic assemblage from Mughr el-Hamamah Layer B support the suggestion that different EUP core reduction technologies_-usually attributed to stratigraphically successive IUP/Emiran and Early Ahmarian industries, respectively — were contemporaneously adopted in the Levant in the $45-40 \mathrm{ka}$ timeframe. The techno-typological variation documented for the Kebara Units IV-III, Mughr elHamamah Layer B, and Tor Fawaz EUP assemblages—among others (Davidzon and GoringMorris, 2003; cf. Garrod, 1951, 1955)—is more complex, conspicuously involving EarlyAhmarian patterns of prismatic blade production (Goring-Morris and Davidzon, 2006). 
Archaeological definitions of lithic industries may not—and probably often do not— correspond to prehistoric social/population boundaries, but reflect instead different residential mobility, curation, and task patterns within and across ecological zones. This underscores the importance of clarifying the chronology and causes of technological variability—for which subdivision into archaeological industries is a rough, perhaps preliminary proxy—across the Levant in the entire LMP-EUP transitional timeframe, ca. 50-40 ka. From this behavioral ecological perspective, hypotheses linking traditionally defined industries to human population expansion waves are plausible (Mellars, 2006; Banks et al., 2013a; Zilhão, 2013), but even if they are part of the story, they probably do not tell the whole story (Brantingham et al., 2004; Tostevin, 2012; Kuhn, 2013).

Indeed, the documentation of newly identified patterns of EUP technological variation in MHM Layer B raises new questions about how LMP-EUP behavioral change was systemically related to anatomically modern human-Neandertal population biological turnover. Where hominin fossils are preserved in associated LMP (ca. 75-50/45 ka) Levantine archaeological contexts, they exhibit Neandertal anatomical traits, with the well-documented Amud 1 burial having been dated to ca. 55-48 ka and the Kebara Cave Neandertal burial dated to ca. $60 \mathrm{ka}$ (Valladas et al., 1987, 1999; Rink et al., 2001; Rebollo et al., 2011; cf. Stutz, 2014). However, clear associations between Levantine EUP technologies and diagnostic human remains post-date ca. 42-40 ka. Rare Levantine AMH specimens occur stratigraphically with Early Ahmarian assemblages (Bergman and Stringer, 1989; Bar-Yosef and Belfer-Cohen, 2004; Barzilai et al., 2012; Douka et al., 2013; Marder et al., 2013; Kuhn and Zwyns, 2014). As noted above, the chronological position of the Manot 1 anatomically modern calvarium may well fall into the 60 50 ka range, but the U-Th results may also support a substantially older minimum age 
(Hershkovitz et al., 2015). Thus, there remains substantial uncertainty over the finer geographic and chronological structure of the Levantine MP-UP Transition in the 50-40 ka timeframe, with even greater uncertainty over the pattern of AMH-Neandertal biological turnover (Hovers, 2006; Shea, 2008; Kuhn et al., 2009; Rebollo et al., 2011; Hovers and Belfer-Cohen, 2013; Kuhn and Zwyns, 2014; Stutz, 2014).

We emphasize that the Jordan Valley is the ecologically richest area of the Levant. It is also one of the very few geographic zones within the region that, until recently, had not revealed an EUP site with substantial stratigraphy or chronometric data. With ongoing analyses and planned further excavation, MHM has substantial potential to expand the archaeological record for residential mobility, foraging strategies, provisioning for combustion fuel, and on-site task diversity and spatial patterns, while also providing new insights into variation in the environmental contexts of EUP biocultural adaptations during the crucial ca. 50-40 ka period, when western Eurasian AMH-Neandertal biological turnover began to unfold.

\section{Acknowledgements}

We thank co-editor Mark Teaford, the associate editor, and four anonymous reviewers who provided constructive feedback on our submitted manuscript. Gil Tostevin, Nigel Goring-Morris, and Ofer Bar-Yosef provided valuable feedback on earlier versions of the manuscript. Funding for this project was provided by a National Science Foundation High Risk Research in Anthropology grant to AJS and LNS (Grant \#102352), a Leakey Foundation grant to AJS, LNS, JLC and TA, the Faculty Development Committee of Oxford College of Emory University, the Pierce Institute for Leadership and Community Engagement, and a Gregory-Rackley Career Development Award to AJS. The authors thank the following individuals and institutions for critical support and permissions in the field: the Department of Antiquities of Jordan, the 
American Center for Oriental Research, the Council for British Research in the Levant, the Yarmouk University Faculty of Archaeology and Anthropology, Dr. Jaimie Lovell, Rami Freihat, Ahmed and Nada Joudeh, and Jaimoe.

\section{References}

Ahmad, G.S., Shea, J.J., 2009. Reconstructing Late Pleistocene Human Behavior in the Jordan Rift Valley: The Middle Paleolithic Stone Tool Assemblage from Ar Rasfa. British Archaeological Reports BAR International Series. Archaeopress, Oxford.

Banks, W.E., d' Errico, F., Zilhão, J., 2013a. Human-climate interaction during the Early Upper Paleolithic: testing the hypothesis of an adaptive shift between the Proto-Aurignacian and the Early Aurignacian. J. Hum. Evol. 64, 39-55.

Banks, W.E., d' Errico, F., Zilhão, J., 2013b. Revisiting the chronology of the Proto-Aurignacian and the Early Aurignacian in Europe: A reply to Higham et al.'s comments on. J. Hum. Evol. 65, 810-817.

Bar-Yosef, O., 2000. The impact of radiocarbon dating on old world archaeology : Past achievements and future expectations. Radiocarbon 42, 23-39.

Bar-Yosef, O., Belfer-Cohen, A., 2010. The Levantine Upper Palaeolithic and Epipaleolithic. In: Garcia, E.A.A. (Ed.), South-Eastern Mediterranean Peoples Between 130,000 and 10,000 Years Ago. Oxbow, Oxford, pp. 144-167.

Bar-Yosef, O., Meignen, L. (Eds.), 2007. Kebara Cave, Mt. Carmel, Israel: The Middle and Upper Paleolithic Archaeology, Part I, American School of Prehistoric Research Bulletin. Peabody Museum of Archaeology and Ethnology, Harvard University, Cambridge. 
Bar-Yosef, O., Vandermeersch, B., 1972. The stratigraphic and cultural problems of the passage from the Middle to Upper Paleolithic in Palestinian Caves. In: Bordes, F. (Ed.), The Origins of Homo Sapiens. UNESCO, Paris, pp. 221-225.

Bar-Yosef, O., Vandermeersch, B., Arensburg, B., Belfer-Cohen, A., Goldberg, P., Laville, H., Meignen, L., Rak, Y., Speth, J.D., Tchernov, E., Tillier, A.-M., Weiner, S., Clark, G.A., Garrard, A., Henry, D.O., Hole, F., Roe, D., Rosenberg, K.R., Schepartz, L.A., Shea, J.J., Smith, F.H., Trinkaus, E., Whalen, N.M., Wilson, L., 1992. The excavations in Kebara Cave, Mt. Carmel [and Comments and Replies]. Curr. Anthropol. 33, 497-550.

Bar-Yosef, O., Arnold, M., Mercier, N., Belfer-Cohen, A., Goldberg, P., Housley, R., Laville, H., Meignen, L., Vogel, J.C., Vandermeersch, B., 1996. The dating of the Upper Paleolithic layers in Kebara Cave, Mt Carmel. J. Archaeol. Sci. 23, 297-306.

Bartov, Y., Stein, M., Enzel, Y., Agnon, A., Reches, Z., 2002. Lake levels and sequence stratigraphy of Lake Lisan, the Late Pleistocene precursor of the Dead Sea. Quatern. Res. 57, 9-21.

Barzilai, O., Hershkovitz, I., Marder, O., Ayalon, A., Bar-Matthews, M., Bar-Oz, G., Boaretto, E., Berna, F., Frumkin, A., Khalaily, H., Weiner, S., Yeshurun, R., 2012. Manot Cave (Preliminary Report No. Vol. 124), Hadashot Arkheologiyot: Excavations and Surveys in Israel. Israel Antiquities Authority, Jerusalem.Bergman, C.A., 1988. Ksar Akil and the Upper Palaeolithic of the Levant. Paléorient 14, 201-210.

Bergman, C., Stringer, C., 1989. Fifty years after: Egbert, an early Upper Palaeolithic juvenile from Ksar Akil, Lebanon. Paléorient 15, 99-111. 
Bird, M.I., Ayliffe, L.K., Fifield, L.K., Turney, C.M., Cresswell, R.G., Barrows, T.T., David, B., 1999. Radiocarbon dating of "old" charcoal using a wet oxidation, stepped-combustion procedure. Radiocarbon 41, 127-140.

Brantingham, P.J., Kuhn, S.L., Kerry, K.W., 2004. On the difficulty of Middle-Upper Paleolithic transitions. In: Brantingham, P.J., Kuhn, S.L., Kerry, K.W. (Eds.), The Early Upper Paleolithic Beyond Western Europe. University of California Press, Berkeley, pp. 1-13.

Brock, F., Higham, T.F.G., 2011. AMS radiocarbon dating of Paleolithic-aged charcoal from Europe and the Mediterranean rim using ABOx-SC. Radiocarbon 51, 839-846.

Coinman, N.R., 1993. WHS 618 - Ain el-Buhira: An Upper Paleolithic site in the Wadi el-Hasa, west-central Jordan. Paléorient 19, 17-37.

Coinman, N.R., 2000. The Upper Paleolithic in the Wadi al-Hasa. In: Coinman, N.R. (Ed.), The Archaeology of the Wadi Al-Hasa, West Central Jordan. Arizona State University, Tempe, pp. 143-159.

Coinman, N.R., 2002. New evidence of Ksar Akil scrapers in the Levantine Upper Paleolithic. Paléorient 28, 87-103.

Coinman, N.R., Henry, D.O., 1995. The Upper Paleolithic sites. In: Henry, D.O. (Ed.), Prehistoric Cultural Ecology and Evolution: Insights from Southern Jordan. Plenum Press, New York, pp. 133-214.

Copeland, L., 2000. Forty-six Emireh points from the Lebanon in the context of the Middle to Upper Paleolithic transition in the Levant. Paléorient 26, 73-92.

Davidzon, A., Goring-Morris, A.N., 2003. Sealed in stone: the Upper Palaeolithic Early Ahmarian knapping method in the light of refitting studies at Nahal Nizzana XIII, Western Negev, Israel. J. Israel Prehist. Soc. 33, 75-205. 
Douka, K., 2011. An Upper Palaeolithic shell scraper from Ksar Akil (Lebanon). J. Archaeol. Sci. $38,429-437$.

Douka, K., Hedges, R.M., Higham, T.G., 2010. Improved AMS 14C dating of shell carbonates using high-precision x-ray diffraction and a novel density separation protocol (CarDS). Radiocarbon 52, 735-751.

Douka, K., Bergman, C.A., Hedges, R.E.M., Wesselingh, F.P., Higham, T.F.G., 2013. Chronology of Ksar Akil (Lebanon) and implications for the colonization of Europe by anatomically modern humans. PLoS ONE 8, e72931.

Fox, J.R., Coinman, N.R., 2004. Emergence of the Levantine Upper Paleolithic: Evidence from the Wadi al-Hasa. In: Brantingham, P.J., Kuhn, S.L., Kerry, K.W. (Eds.), The Early Upper Paleolithic Beyond Western Europe. University of California Press, Berkeley, pp. $97-112$.

Froehle, A.W., Yokley, T.R., Churchill, S.E., 2013. Energetics and the origin of modern humans. In: Smith, F.H., Ahern, J.C.M. (Eds.), The Origins of Modern Humans: Biology Reconsidered. John Wiley and Sons, New York, pp. 285-320.

Garrod, D.A.E., 1951. A transitional industry from the base of the Upper Palæolithic in Palestine and Syria. J. R. Anthropol. Inst. 81, 121-130.

Garrod, D.A.E., 1955. The Mugharet el-Emireh in Lower Galilee: type station of the Emiran Industry. J. R. Anthropol. Inst. 85, 141-162.

Goldberg, P., Meignen, L., Mallol, C., 2009. Geoarchaeology, site formation, and transitions. In: Shea, J.J., Lieberman, D.E. (Eds.), Transitions in Prehistory: Essays in Honor of Ofer Bar-Yosef. Oxbow, Oxford, pp. 431-443. 
Goring-Morris, A.N., Belfer-Cohen, A., 2003. More Than Meets the Eye: Studies on Upper Palaeolithic Diversity in the Near East. Oxbow, Oxford.

Goring-Morris, A.N., Belfer-Cohen, A., 2006. A hard look at the "Levantine Aurignacian": How real is the taxon? In: Bar-Yosef, O., Zilhão, J. (Eds.), Towards a Definition of the Aurignacian: Proceedings of the Symposium Held in Lisbon, Portugal, June 25-30, 2002, Trabalhos de Arqueologia. Instituto Português de Arqueologia, Lisbon, pp. 297-314.

Goring-Morris, N., Davidzon, A., 2006. Straight to the point : Upper paleolithic Ahmarian lithic technology in the Levant. Anthropologie 44, 93-111.

Goring-Morris, N., Hovers, E., Belfer-Cohen, A., 2009. The dynamics of Pleistocene and early Holocene settlement patterns and human adaptations in the Levant: an overview. In: Shea, J.J., Lieberman, D. (Eds.), Transitions in Prehistory: Essays in Honor of Ofer BarYosef. Oxbow Books on behalf of the American School of Prehistoric Research, Oxford, pp. $185-252$.

Henry, D.O., 1995. Prehistoric Cultural Ecology and Evolution: Insights from Southern Jordan. Plenum Press, New York.

Hershkovitz, I., Marder, O., Ayalon, A., Bar-Matthews, M., Yasur, G., Boaretto, E., Caracuta, V., Alex, B., Frumkin, A., Goder-Goldberger, M., Gunz, P., Holloway, R.L., Latimer, B., Lavi, R., Matthews, A., Slon, V., Mayer, D.B.-Y., Berna, F., Bar-Oz, G., Yeshurun, R., May, H., Hans, M.G., Weber, G.W., Barzilai, O., 2015. Levantine cranium from Manot Cave (Israel) foreshadows the first European modern humans. Nature. 520, 216-219. http://dx.doi.org/10.1038/nature14134. 
Higham, T., Brock, F., Peresani, M., Broglio, A., Wood, R., Douka, K., 2009. Problems with radiocarbon dating the Middle to Upper Palaeolithic transition in Italy. Quatern. Sci. Rev. $28,1257-1267$.

Higham, T., Wood, R., Moreau, L., Conard, N., Ramsey, C.B., 2013. Comments on "Humanclimate interaction during the early Upper Paleolithic: Testing the hypothesis of an adaptive shift between the Proto-Aurignacian and the Early Aurignacian” by Banks et al. J. Hum. Evol. 65, 806-809.

Hovers, E., 2006. Neandertals and modern humans in the Middle Paleolithic of the Levant: What kind of interaction? In: Conard, N.J. (Ed.), When Neandertals and Modern Humans Met. Kerns Verlag, Tübingen, pp. 65-86.

Hovers, E., Belfer-Cohen, A., 2013. On variability and complexity: Lessons from the Levantine Middle Paleolithic record. Curr. Anthropol. 54, S337-S357.

Hovers, E., Malinsky-Buller, A., Ekshtain, R., Oron, M., Yeshurun, R., 2009. 'Ein Qashish - a new open-air Middle Paleolithic site in northern Israel. J. Isr. Prehist. Soc. 38, 7-40.

Jenkins, D., 2009. Cubic Splines. Newton Excel Bach. https://newtonexcelbach.wordpress.com/2009/07/02/cubic-splines/

Kadowaki, S., 2013. Issues of chronological and geographical distributions of Middle and Upper Paleolithic cultural variability and implications for the learning behavior of Neanderthals and Homo sapiens. In: Akazawa, T., Nishiaki, Y., Aoki, K. (Eds.), Dynamics of Learning in Neanderthals and Modern Humans Volume 1: Cultural Perspectives. Springer, New York, pp. 59-91.

Kerry, K.W., Henry, D.O., 2003. Tor Fawaz (J403): An Upper Paleolithic occupation in the Jebel Qalkha Area, Southwest Jordan. In: Goring-Morris, A.N., Belfer-Cohen, A. (Eds.), 
More Than Meets the Eye: Studies on Upper Palaeolithic Diversity in the Near East. Oxbow, Oxford, pp. 171-184.

Kuhn, S.L., 1991. "Unpacking" reduction: Lithic raw material economy in the Mousterian of west-central Italy. J. Anthropol. Archaeol. 10, 76-106.

Kuhn, S.L., 1992. On planning and curated technologies in the Middle Paleolithic. J. Anthropol. Res. $48,185-214$.

Kuhn, S.L., 2013. Questions of complexity and scale in explanations for cultural transitions in the Pleistocene: A case study from the early Upper Paleolithic. J. Archaeol. Method Th. 20, 194-211.

Kuhn, S.L., Stiner, M.C., 2006. What's a mother to do? The division of labor among Neandertals and modern humans in Eurasia. Curr. Anthropol. 47, 953-981.

Kuhn, S.L., Zwyns, N., 2014. Rethinking the initial Upper Paleolithic. Recent advances in studies of the late Pleistocene and Palaeolithic of Northeast Asia. Quatern. Int. 347, 2938.

Kuhn, S.L., Stiner, M.C., Güleç, E., Özer, I., Yılmaz, H., Baykara, I., Açıkkol, A., Goldberg, P., Molina, K.M., Ünay, E., Suata-Alpaslan, F., 2009. The early Upper Paleolithic occupations at Üçağızlı Cave (Hatay, Turkey). J. Hum. Evol. 56, 87-113.Lengyel, G., Boaretto, E., Fabre, L., Ronen, A., 2006. New AMS ${ }^{14} \mathrm{C}$ dates from the Early Upper Paleolithic sequence of Raqefet Cave, Mount Carmel, Israel. Radiocarbon 48, 253-258.

Lisker, S., Vaks, A., Bar-Matthews, M., Porat, R., Frumkin, A., 2009. Stromatolites in caves of the Dead Sea Fault Escarpment: implications to latest Pleistocene lake levels and tectonic subsidence. Quatern. Sci. Rev. 28, 80-92.

Lovell, J., 2009. Chalcolithic caves discovered east of the River Jordan. Antiquity 083. 
Marder, O., Alex, B., Ayalon, A., Bar-Matthews, M., Bar-Oz, G., Bar-Yosef Mayer, D., Berna, F., Boaretto, E., Caracuta, V., Latimer, B., Lavi, R., Matthews, A., Weiner, S., Weiss, U., Yas'ur, G., Yeshurun, R., Barzilai, O., 2013. The Upper Palaeolithic of Manot Cave, Western Galilee, Israel: the 2011-12 excavations. Antiquity 087, Project Gallery.

Marks, A.E., 1977a. The Upper Paleolithic sites of Boker Tachtit and Boker: a preliminary report, in: Prehistory and Paleoenvironments in the Central Negev, Israel, Volume II: The Avdat/Aqev Area, Part 2, and the Har Harif. Southern Methodist University, Dallas, pp. $61-79$.

Marks, A.E., 1977b. Prehistory and Paleoenvironments in the Central Negev, Israel: The Avdat/Aqev Area, Part 2, and the Har Harif. Southern Methodist University, Dallas.

Marks, A.E., 1983. Prehistory and Paleoenvironment in the Central Negev, Israel, Vol. 3. Southern Methodist University, Dallas.

Marks, A.E., 2003. Reflections on Levantine Upper Paleolithic studies: Past and present. In: Goring-Morris, A.N., Belfer-Cohen, A. (Eds.), More Than Meets the Eye: Studies on Upper Palaeolithic Diversity in the Near East. Oxbow, Oxford, pp. 249-264.

Meignen, L., 2012. Levantine perspectives on the Middle to Upper Paleolithic "Transition". Archaeol. Ethnol. Anthropol. Eurasia 40, 12-21.

Mellars, P., 2006. Archeology and the dispersal of modern humans in Europe: Deconstructing the "Aurignacian". Evol. Anthropol. 15, 167-182.

Monigal, K., 2003. Monigal, K., 2003. Technology, economy, and mobility at the beginning of the Levantine Upper Paleolithic. In: Goring-Morris, A.N., Belfer-Cohen, A. (Eds.), More Than Meets the Eye: Studies on Upper Palaeolithic Diversity in the Near East. Oxbow Books, Oxford, pp. 118-133. 
Niu, M., 2013. The Bayesian approach to radiocarbon calibration curve estimation: The IntCal13, Marine13, and SHCal13 Methodologies. Radiocarbon 55, 1905-1922.

Ohnuma, K., Bergman, C., 1990. A technological analysis of the Upper Palaeolithic levels (XXV-VI) of Ksar Akil, Lebanon. In: Mellars, P., Stringer, C.B. (Eds.), The Emergence of Modern Humans: An Archaeological Perspective. Edinburgh University Press, Edinburgh, pp. 91-138.

Pigati, J.S., Quade, J., Wilson, J., Jull, A.J.T., Lifton, N.A., 2007. Development of lowbackground vacuum extraction and graphitization systems for 14C dating of old (40$60 \mathrm{ka})$ samples. Quatern. Int. 166, 4-14.

Pinhasi, R., Higham, T.F.G., Golovanova, L.V., Doronichev, V.B., 2011. Revised age of late Neanderthal occupation and the end of the Middle Paleolithic in the northern Caucasus. Proc. Natl. Acad. Sci. 108, 8611-8616.

Ploux, S., Soriano, S., 2003. Umm el Tlel, une séquence du Paléolithique supérieur en Syrie centrale. Industries lithiques et chronologie culturelle. Paléorient 29, 5-34.

Ramsey, C.B., 2001. Development of the radiocarbon calibration program. Radiocarbon 43, $355-363$.

Ramsey, C.B., Scott, M., van der Plicht, H., 2013. Calibration for archaeological and environmental terrestrial samples in the time range 26-50 ka cal BP. Radiocarbon 55, 2021-2027.

Rebollo, N.R., Cohen-Ofri, I., Popovitz-Biro, R., Bar-Yosef, O., Meignen, L., Goldberg, P., Weiner, S., Boaretto, E., 2008. Structural characterization of charcoal exposed to high and low $\mathrm{pH}$ : Implications for $14 \mathrm{C}$ sample preparation and charcoal preservation. Radiocarbon 50, 289-307. 
Rebollo, N.R., Weiner, S., Brock, F., Meignen, L., Goldberg, P., Belfer-Cohen, A., Bar-Yosef, O., Boaretto, E., 2011. New radiocarbon dating of the transition from the Middle to the Upper Paleolithic in Kebara Cave, Israel. J. Archaeol. Sci. 38, 2424-2433.

Rech, J.A., Pigati, J.S., Lehmann, S.B., McGimpsey, C.N., Grimley, D.A., Nekola, J.C., 2011. Assessing open-system behavior of $14 \mathrm{C}$ in terrestrial gastropod shells. Radiocarbon 53, $325-335$.

Reimer, P., Bard, E., Bayliss, A., Beck, J.W., Blackwell, P.G., Ramsey, C.B., Buck, C.E., Cheng, H., Edwards, R.L., Friedrich, M., Grootes, P.M., Guilderson, T.P., Haflidi, H., Hajdas, I., Hatté, C., Heaton, T.J., Hoffmann, D.L., Hogg, A.G., Hughen, K.A., Kaiser, K.F., Kromer, B., Manning, S.W., Niu, M., Reimer, R.W., Richards, D.A., Scott, E.M., Southon, J.R., Staff, R.A., Turney, C.S.M., van der Plicht, J., 2013. IntCal13 and Marine13 radiocarbon age calibration curves 0-50,000 Years cal BP. Radiocarbon 55, $1869-1887$.

Richter, D., Tostevin, G., Škrdla, P., Davies, W., 2009. New radiometric ages for the Early Upper Palaeolithic type locality of Brno-Bohunice (Czech Republic): comparison of OSL, IRSL, TL and 14C dating results. J. Archaeol. Sci. 36, 708-720.

Richter, T., Stutz, A.J., Nilsson Stutz, L.G., el-Balawnh, M., 2009. Mughur al- Hamamah: A Prehistoric Cave Site in the Western 'Ajlun District, Report on the Initial Survey Season. Annual of the Department of Antiquities of Jordan, 53, 73-82.

Rink, W.J., Schwarcz, H. p., Lee, H. k., Rees-Jones, J., Rabinovich, R., Hovers, E., 2001. Electron spin resonance (ESR) and thermal ionization mass spectrometric (TIMS) 230Th/234U dating of teeth in Middle Paleolithic layers at Amud Cave, Israel. Geoarchaeology 16, 701-717. 
Schwarcz, H.P., Buhay, W.M., Grün, R., Valladas, H., Tchernov, E., Bar-Yosef, O., Vandermeersch, B., 1989. ESR dating of the Neanderthal site, Kebara Cave, Israel. J. Archaeol. Sci. 16, 653-659.

Shea, J.J., 2008. Transitions or turnovers? Climatically-forced extinctions of Homo sapiens and Neanderthals in the east Mediterranean Levant. Quatern. Sci. Rev. 27, 2253-2270.

Shea, J.J., 2013. Stone Tools in the Paleolithic and Neolithic of the Near East: A Guide. Cambridge University Press, New York.

Staff, R., 2013. Integration of the old and new Lake Suigetsu (Japan) terrestrial radiocarbon calibration data sets. Radiocarbon 55.

Stiner, M.C., Kuhn, S.L., 1992. Subsistence, technology, and adaptive variation in Middle Paleolithic Italy. Am. Anthropol. 94, 306-339.

Stutz, A.J., 2014. Near East (including Anatolia): Geographic description and general chronology of the Paleolithic and Neolithic. In: Smith, C. (Ed.), Encyclopedia of Global Archaeology. Springer, New York, pp. 5182-5208.

Stutz, A.J., Nilsson Stutz, L.G., Clark, J.L., Arpin, T., Rech, J.A., Robinson, J., 2012. Mughr elHamamah. Am. J. Archaeol. 116, 697-699.

Tostevin, G.B., 2012. Seeing Lithics: A Middle-Range Theory for Testing for Cultural Transmission in the Pleistocene. Oxbow Books, Oxford.

Valladas, H., Joron, J.L., Valladas, G., Arensburg, B., Bar-Yosef, O., Belfer-Cohen, A., Goldberg, P., Laville, H., Meignen, L., Rak, Y., Tchernov, E., Tillier, A.M., Vandermeersch, B., 1987. Thermoluminescence dates for the Neanderthal burial site at Kebara in Israel. Natur. 330, 159-160. 
Valladas, H., Mercier, N., Froget, L., Hovers, E., Joron, J.-L., Kimbel, W.H., Rak, Y., 1999. TL dates for the Neanderthal site of the Amud Cave, Israel. J. Archaeol. Sci. 26, 259-268.

Weiner, S., 2009. Diagenetic transformations: Deciphering the archaeological record of prehistoric caves. In: Shea, J.J., Lieberman, D.E. (Eds.), Transitions in Prehistory: Essays in Honor of Ofer Bar-Yosef. Oxbow, Oxford, pp. 419-430.

Weiner, S., Goldberg, P., Bar-Yosef, O., 1993. Bone preservation in Kebara Cave, Israel using on-site Fourier transform infrared spectrometry. J. Archaeol. Sci. 20, 613-627.

Weninger, B., Jöris, O., 2008. A 14C age calibration curve for the last 60 ka: the Greenland-Hulu U/Th timescale and its impact on understanding the Middle to Upper Paleolithic transition in Western Eurasia. J. Hum. Evol. 55, 772-781.

Weninger, B., Edinborough, K., Clare, L., Jöris, O., 2011. Concepts of probability in radiocarbon analysis. Documenta Praehistorica 38, 1-20.Williams, J.K., Bergman, C.A., 2010. Upper Paleolithic levels XIII-VI (A and B) from the 1937-1938 and 1947-1948 Boston College excavations and the Levantine Aurignacian at Ksar Akil. Paléorient 36, 117-161.

Zilhão, J., 2013. Neandertal-modern human contact in western Eurasia: Issues of dating, taxonomy, and cultural associations. In: Akazawa, T., Nishiaki, Y., Aoki, K. (Eds.), Dynamics of Learning in Neanderthals and Modern Humans Volume 1: Cultural Perspectives. Springer, New York, pp. 21-57. 


\section{Figure Legends}

Figure 1. Key late Middle Paleolithic (LMP) and early Upper Paleolithic (EUP) archaeological sites in the Levant, including those with in situ evidence for Initial Upper Paleolithic or other > 40 ka EUP technology. Key: (MHM) Mughr el-Hamamah (EUP); (1) Kebara Cave (LMP-EUP);

(2) Ksar Akil Rockshelter (LMP-EUP); (3) Umm el-Tlel (LMP-EUP); (4) Tor Faraj Rockshelter (LMP); (5) Amud Cave (LMP); (6) Tor Fawaz Rockshelter (EUP); (7) Boker Tachtit/Boker (EUP); (8) Tor Sadaf Rockshelter (EUP); (9) Manot Cave (EUP with trace MP); (10) Üçağızlı Cave (EUP). Basemaps by user Fulvio314 on it.wikipedia.org, available on Wikimedia

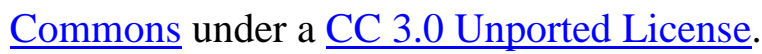

Figure 2. Photograph of Mughr el-Hamamah from the South, including the main cave (Cave 2).

Figure 3. Plan view of Mughr el-Hamamah Cave 2, modified after Richter et al. (2009), with the 2010 test excavation squares shown.

Figure 4. A) Stratigraphic profile of Square C5 West. Here, Layer B is eroding onto the surface. The irregular contour of the Layer B surface on the northern (upper right) portion of the section is due to a removed limestone boulder that overlay Hearths 1 and 2. B) Stratigraphic section photograph of Square B2 West. Visible is the unconformable contact between Layer A and B. Layer A has filled in a twentieth century anthropogenic cut into Layer B. The lack of disturbance in the F-trench north profile indicates that this cut was likely a localized goat-pen ramp to the back chamber. The positions of charcoal samples MHM 2, 4, 5, 7, 8 and 11 are projected onto the sections (see Table 2). 
Figure 5. Squares F2-F4 Northern Profile. The elevation of the contact between Layers A and B in this trench indicates that recent shepherd disturbance has removed the overlying portion of Layer B in the front of the cave, leaving in situ Pleistocene deposits only below ca. $150 \mathrm{~cm}$ below datum.

Figure 6. Cores and blades from Mughr el-Hamamah Layer B. a. burin spall, b. Levallois blade, c.-e. prismatic blades, f. narrow-fronted blade core, g. bladelet core, h. broad-fronted blade core. Arrows indicate proximal-distal orientation of flake scars.

Figure 7. Retouched artifacts from Mughr el-Hamamah Layer B. a. convergent scraper with basal thinning (Emireh point), b. point with partial basal retouch on ventral face (Emireh point), c. Levallois point with distal impact fracture, d. el-Wad point (Ksar Akil point subtype), e. chanfrein retouch flake, f. Ksar Akil scraper, g. endscraper on blade, h. endscraper on cortical blade, i. double endscraper cortical blade, j. double burin on cortical blade, k. multiple burin, 1.m. scaled pieces (bipolar cores on flakes). Arrows indicate proximal-distal orientation of flake scars.

Figure 8. View of Mughr el-Hamamah Cave 2 from the entrance, prior to excavation, June 2010. Visible toward right is the in situ Layer B remnant filling a small bedrock crevice, with the basalt cobble manuport (possibly used as a grinder or hammerstone) sitting undisturbed in a terminus ante quem context. Inset: close-up view of the hammerstone in situ; scale $=10 \mathrm{~cm}$. Charcoal 
sample MHM-6 (Aeon 1028) was carefully pretreated with the ABA protocol, yielding a calibrated date of 36.9-40.6 ka (central 95.4\% of the calibration distribution).

Figure 9. Patterns of charcoal preservation in Mughr el-Hamamah Layer B, in comparison with Kebara Cave Late Middle and Early Upper Paleolithic units. Shown is the percentage mass loss from the $\mathrm{ABOx}$ pretreatment on each sample versus the percentage $\mathrm{CO}_{2}$ yield from combustion. According to Rebollo et al. (2011), all Kebara ABOx-pretreated samples were combusted at 625 ${ }^{\circ} \mathrm{C}$. Two separate points are plotted for sample MHM-5, which lost only $7.11 \%$ of its mass and then yielded substantial amounts of carbon at the 325 and $625^{\circ} \mathrm{C}$ combustion steps. Both MHM5 AMS dates were included in calculating the average calibration curve for MHM Layer B.

Figure 10. The summed calibration distribution for nine ABOx-SC AMS dates on eight in situ charcoal samples from the early Upper Paleolithic Layer B at Mughr el-Hamamah. (Sample MHM-5 yielded two stepped combustion fractions for AMS dating.) The median, central 68.2\% and central $95.4 \%$ of the distribution are marked. Also shown as box-and-whisker plots are the individual sample calibration distributions for the humic acid fraction from sample MHM-10 and the ABA-pretreated AMS date on MHM-6, recovered from a clear terminus ante quem context. 
Tables

Table 1. Microfaunal species present in Mughr el-Hamamah Layer B.

\begin{tabular}{llrr}
\hline \multicolumn{1}{c}{ Order } & Genus/Species & Count $^{1,2}$ & $\%$ \\
\hline \multirow{2}{*}{ Microchiroptera } & cf. Myotis & 1 & 4.0 \\
& Rhinolophus sp. & 1 & 4.0 \\
Insectivora & Crocidura sp. & 2 & 8.0 \\
& Meriones tristrami & 10 & 40.0 \\
\multirow{3}{*}{ Rodentia } & Mus macedonicus & 1 & 4.0 \\
& Sciurus anomalus & \\
& Total & 10 & 40.0 \\
& & 25 & 100.0 \\
\hline
\end{tabular}

${ }^{1}$ Number of in situ cranial specimens from the Squares B5-C5 microfaunal sample identified to taxon.

${ }^{2}$ The identified taxa comprise a presence profile most similar to micromammal communities inhabiting Mediterranean/oak forest vegetation zones during the Middle Paleolithic, with a cooler and wetter climate than in the present-day southern Levant.

${ }^{3}$ The Syrian squirrel, S. anomalus, is only extant in Jordan today on the Transjordanian Plateau, at elevations > ca. $1000 \mathrm{~m}$ asl, where preferred habitat of denser broad-leaf and mixed forests and colder winters prevail. Mughr el-Hamamah is situated at ca. $80 \mathrm{~m}$ asl, closer to the Jordan Valley upper terrace (the Ghor, ca. $-200 \mathrm{~m}$ asl). 
Table 2. Detailed provenience information on the Mughr el-Hamamah charcoal samples.

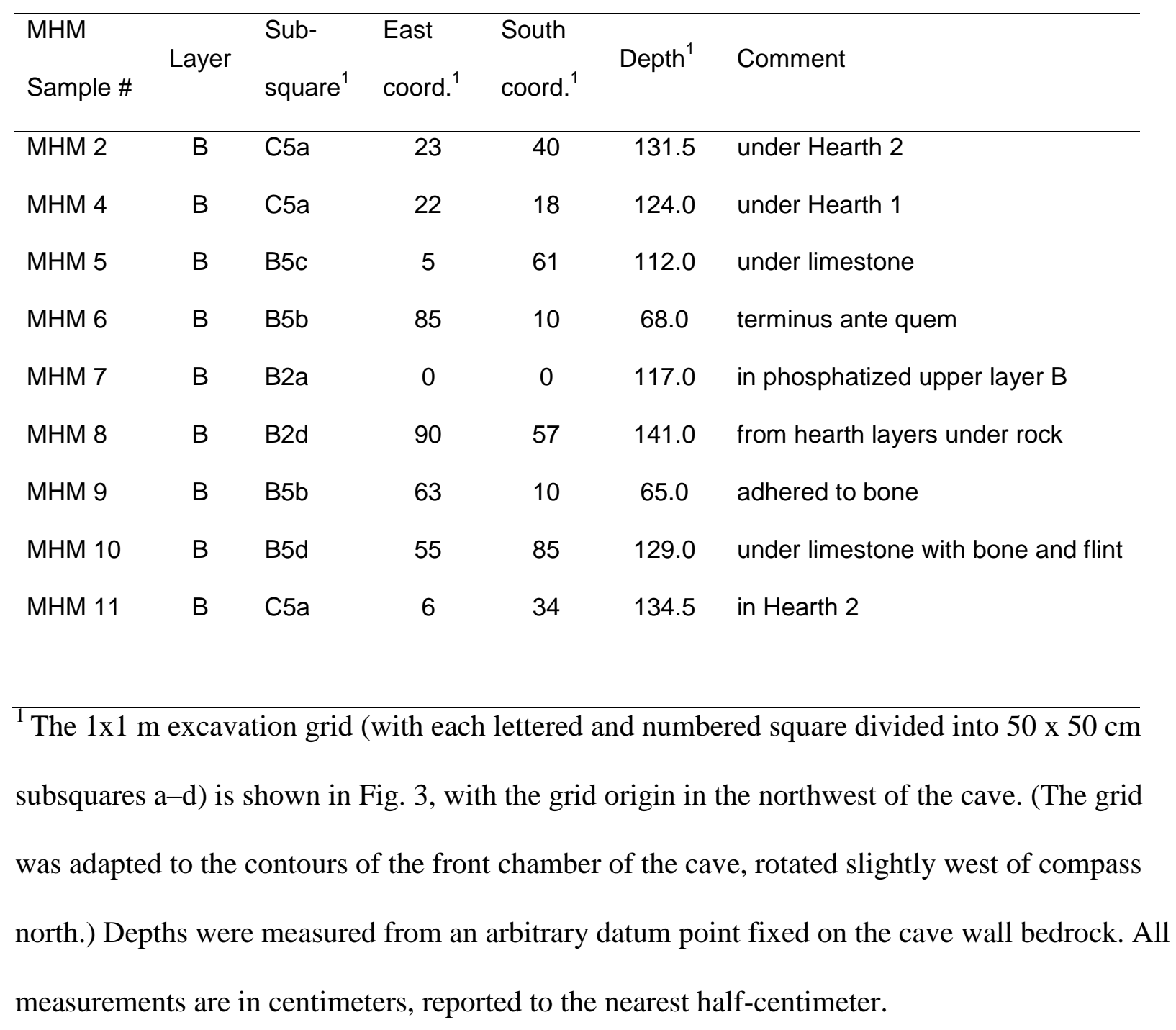


Table 3. Mughr el-Hamamah early Upper Paleolithic AMS ${ }^{14} \mathrm{C}$ assay results.

\begin{tabular}{|c|c|c|c|c|c|}
\hline Sample $\#^{1}$ & Lab ID & $\begin{array}{l}\text { Material } \\
\text { dated }\end{array}$ & $\begin{array}{l}\text { Temp } \\
\left({ }^{\circ} \mathrm{C}\right)^{2}\end{array}$ & Treatment & ${ }^{14} \mathrm{C}$ age $\left({ }^{14} \mathrm{C}\right.$ ka $\left.\mathrm{BP}\right)$ \\
\hline MHM-2 & Aeon-1023 & charcoal & 325 & $\mathrm{ABOx}$ & $36.88 \pm 0.78$ \\
\hline MHM-4 & Aeon-1024 & charcoal & 325 & $\mathrm{ABOx}$ & $38.49 \pm 0.91$ \\
\hline MHM-5 & Aeon-1025 & charcoal & 325 & $\mathrm{ABOx}$ & $36.90 \pm 1.2$ \\
\hline MHM-5 & Aeon-1026 & charcoal & 625 & $\mathrm{ABO} x$ & $39.70 \pm 1.1$ \\
\hline MHM-6 & Aeon-1028 & charcoal & 625 & ABA & $33.89 \pm 0.72$ \\
\hline MHM-7 & Aeon-1032 & charcoal & 325 & $\mathrm{ABOx}$ & $36.01 \pm 0.86$ \\
\hline MHM-8 & Aeon-1033 & charcoal & 325 & $\mathrm{ABOx}$ & $37.10 \pm 0.90$ \\
\hline МHM-9 & Aeon-1034 & charcoal & 325 & $\mathrm{ABOx}$ & $36.33 \pm 0.80$ \\
\hline MHM-10 & Aeon-1035 & charcoal & 325 & $\mathrm{ABOx}$ & $39.50 \pm 1.0$ \\
\hline MHM-10 & Aeon-1038 & humic acids & 625 & -- & $37.21 \pm 0.79$ \\
\hline MHM-11 & Aeon-1036 & charcoal & 325 & $A B O x$ & $38.50 \pm 1.2$ \\
\hline
\end{tabular}


Table 4. Mughr el-Hamamah early Upper Paleolithic calibrated ${ }^{14} \mathrm{C}$ dates.

\begin{tabular}{|c|c|c|c|}
\hline \multirow[b]{2}{*}{ Lab ID } & \multicolumn{3}{|c|}{ calibrated years $\mathrm{BP}^{1}$} \\
\hline & 0.023 & 0.5 & 0.977 \\
\hline Aeon-1023 & 40,263 & 41,751 & 42,851 \\
\hline Aeon-1024 & 41,638 & 42,901 & 44,282 \\
\hline Aeon-1025 & 39,153 & 41,667 & 43,517 \\
\hline Aeon-1026 & 42,200 & 43,747 & 45,320 \\
\hline Aeon-1028 & 36,913 & 38,743 & 40,599 \\
\hline Aeon-1032 & 39,044 & 40,982 & 42,304 \\
\hline Aeon-1033 & 40,180 & 41,897 & 43,188 \\
\hline Aeon-1034 & 39,418 & 41,302 & 42,477 \\
\hline Aeon-1035 & 42,197 & 43,616 & 45,063 \\
\hline Aeon-1038 & 40,669 & 41,993 & 43,107 \\
\hline Aeon-1036 & 41,153 & 42,921 & 44,650 \\
\hline
\end{tabular}

${ }^{1}$ Shown are the median, the older bound (green) and the younger bound (yellow) for the central 95.4\% of the calibration probability distribution for each assay. 
Table 5. Radiometric Chronological Evidence for the Earliest Upper Paleolithic in the Levant

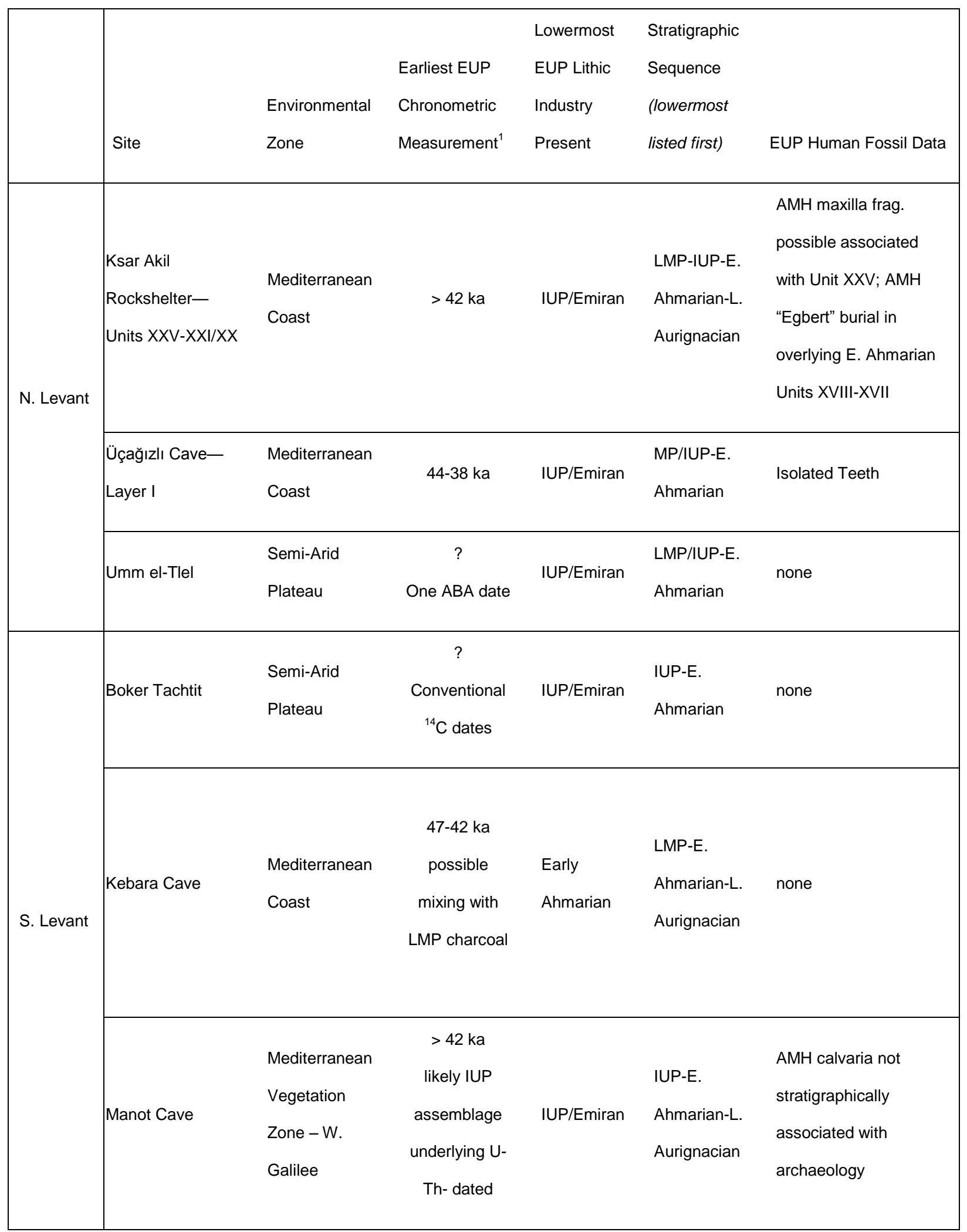




\begin{tabular}{|c|c|c|c|c|c|}
\hline \multicolumn{6}{|c|}{ flowstone } \\
\hline $\begin{array}{l}\text { Mughr el- } \\
\text { Hamamah- } \\
\text { Layer B }\end{array}$ & Jordan Valley & 45-39 ka & $\begin{array}{l}\text { EUP - no } \\
\text { industry yet } \\
\text { assigned }\end{array}$ & EUP & $\begin{array}{l}\text { Isolated Teeth and } \\
\text { Vertebra Fragment }\end{array}$ \\
\hline Tor Fawaz & $\begin{array}{l}\text { Semi-Arid } \\
\text { Plateau }\end{array}$ & $<45 \mathrm{ka}$ & $\begin{array}{l}\text { Early } \\
\text { Ahmarian? }\end{array}$ & E. Ahmarian & none \\
\hline Tor Sadaf & $\begin{array}{l}\text { Semi-Arid } \\
\text { Plateau }\end{array}$ & none & IUP/Emiran & $\begin{array}{l}\text { IUP-E. } \\
\text { Ahmarian }\end{array}$ & none \\
\hline
\end{tabular}

${ }^{1}$ Sites with only conventional ${ }^{14} \mathrm{C}$ measurements or ABA-pretreated AMS assays are conservatively excluded from the chronometric data summary, because small amounts of contamination can cause large deviations in ${ }^{14} \mathrm{C}$ levels, either by diluting the sample with older carbon or enriching it in younger material. These sites may be generally bracketed to the 50-30 ka EUP timeframe, likely with lowermost EUP occupations dating to > $40 \mathrm{ka}$. 


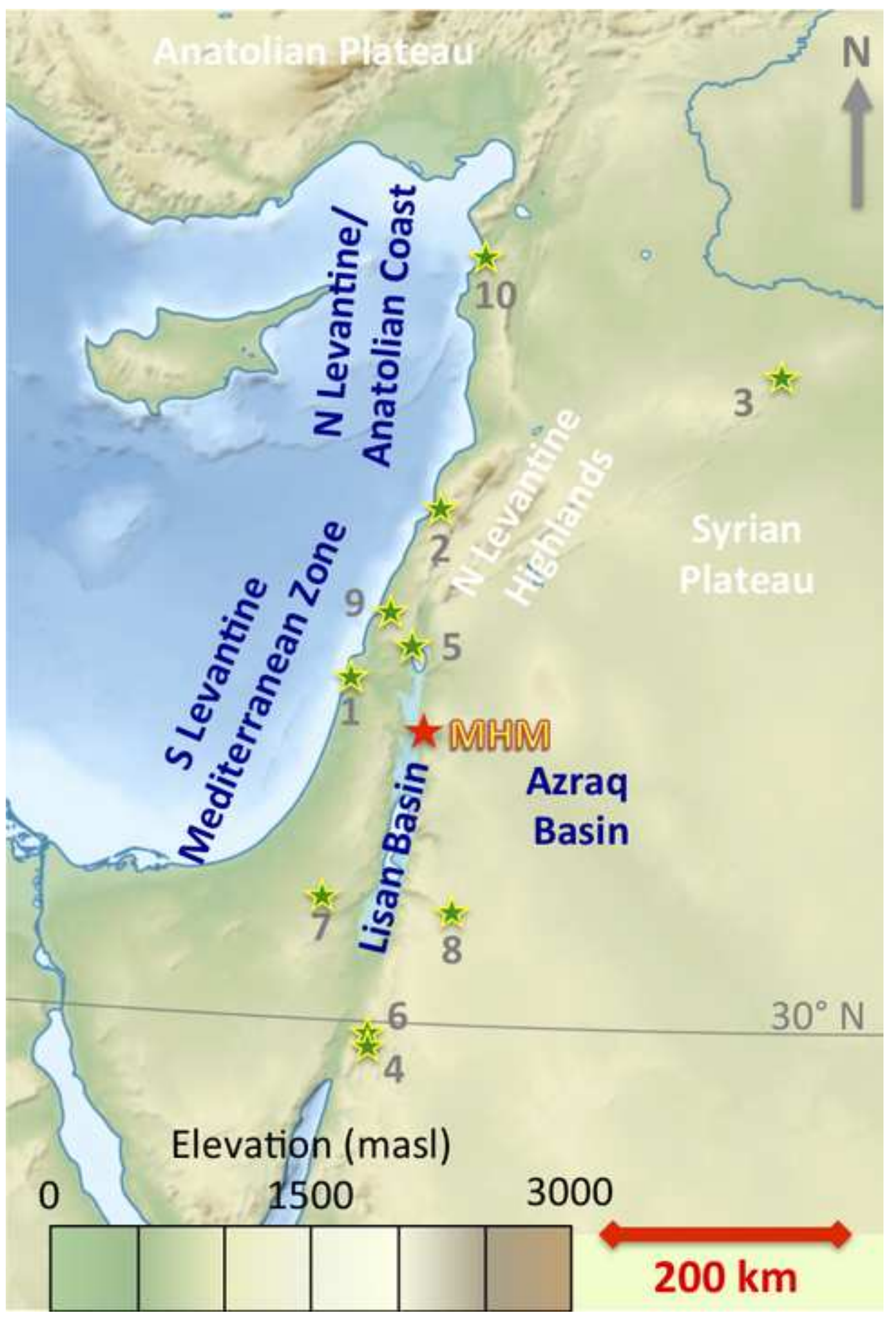

Elevation (masl) 


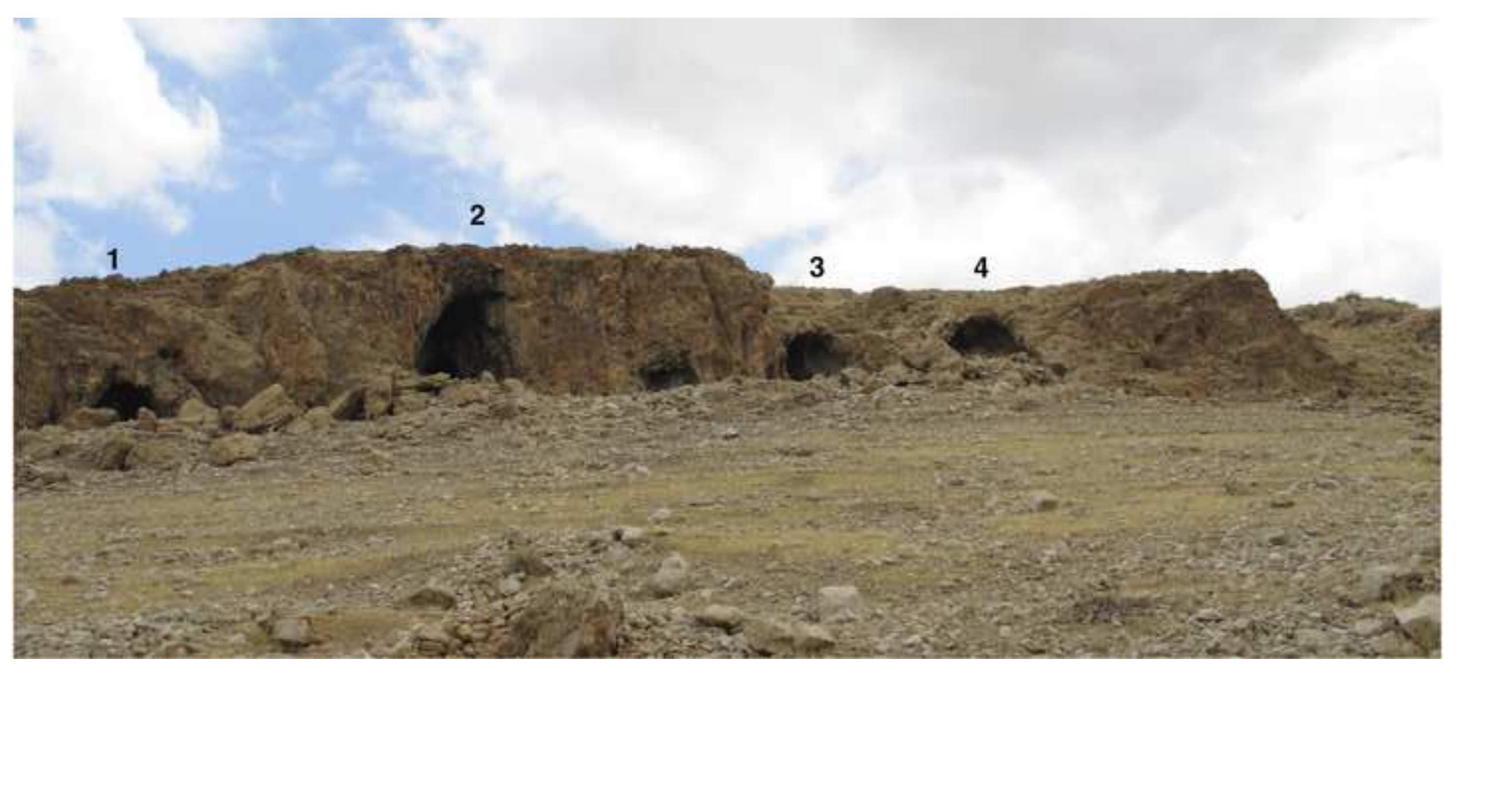

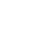

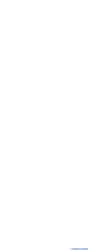

\section{Figure 2}
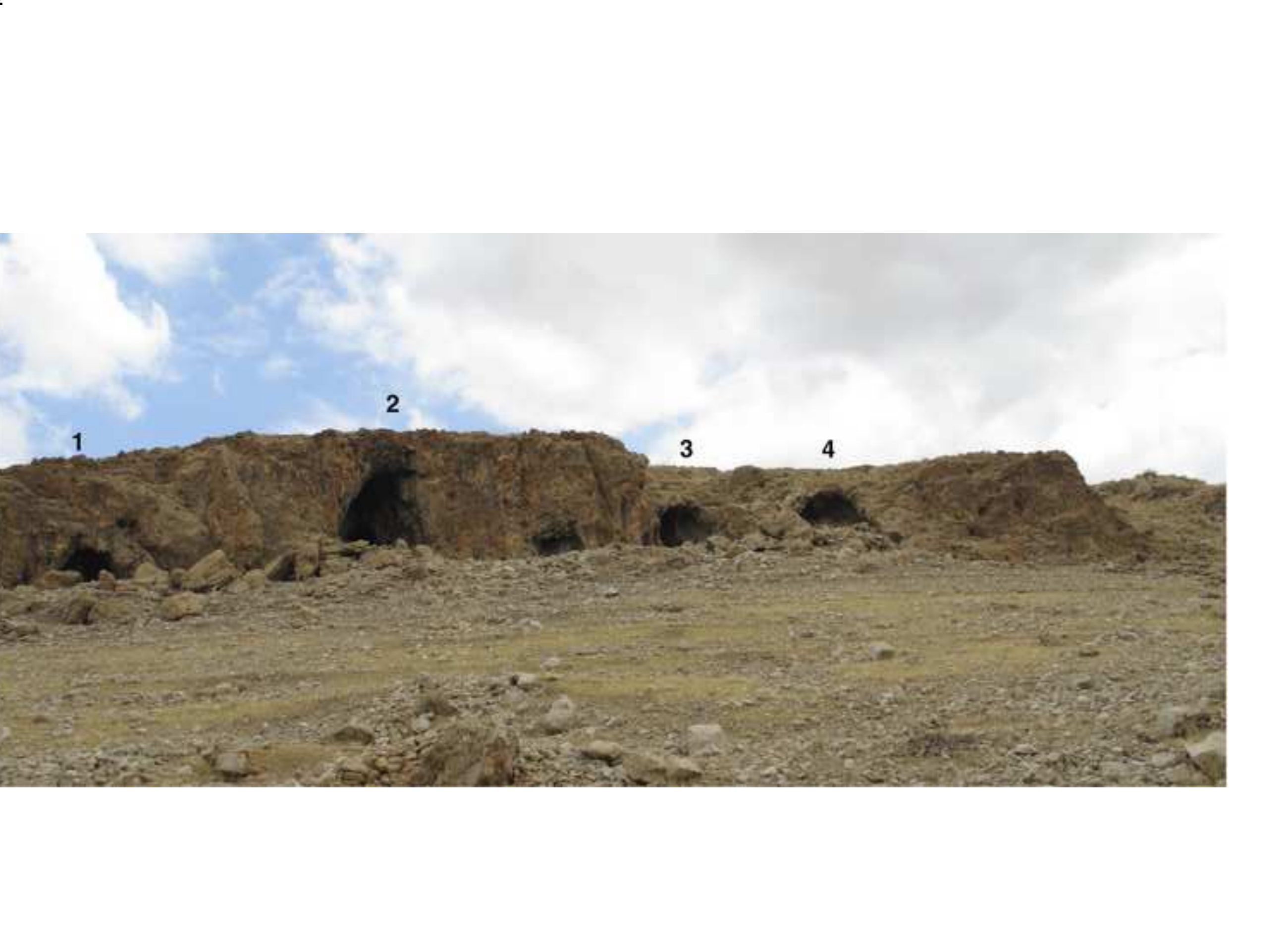

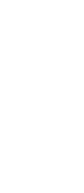
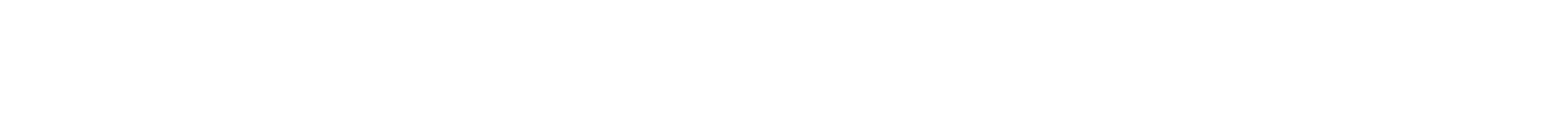


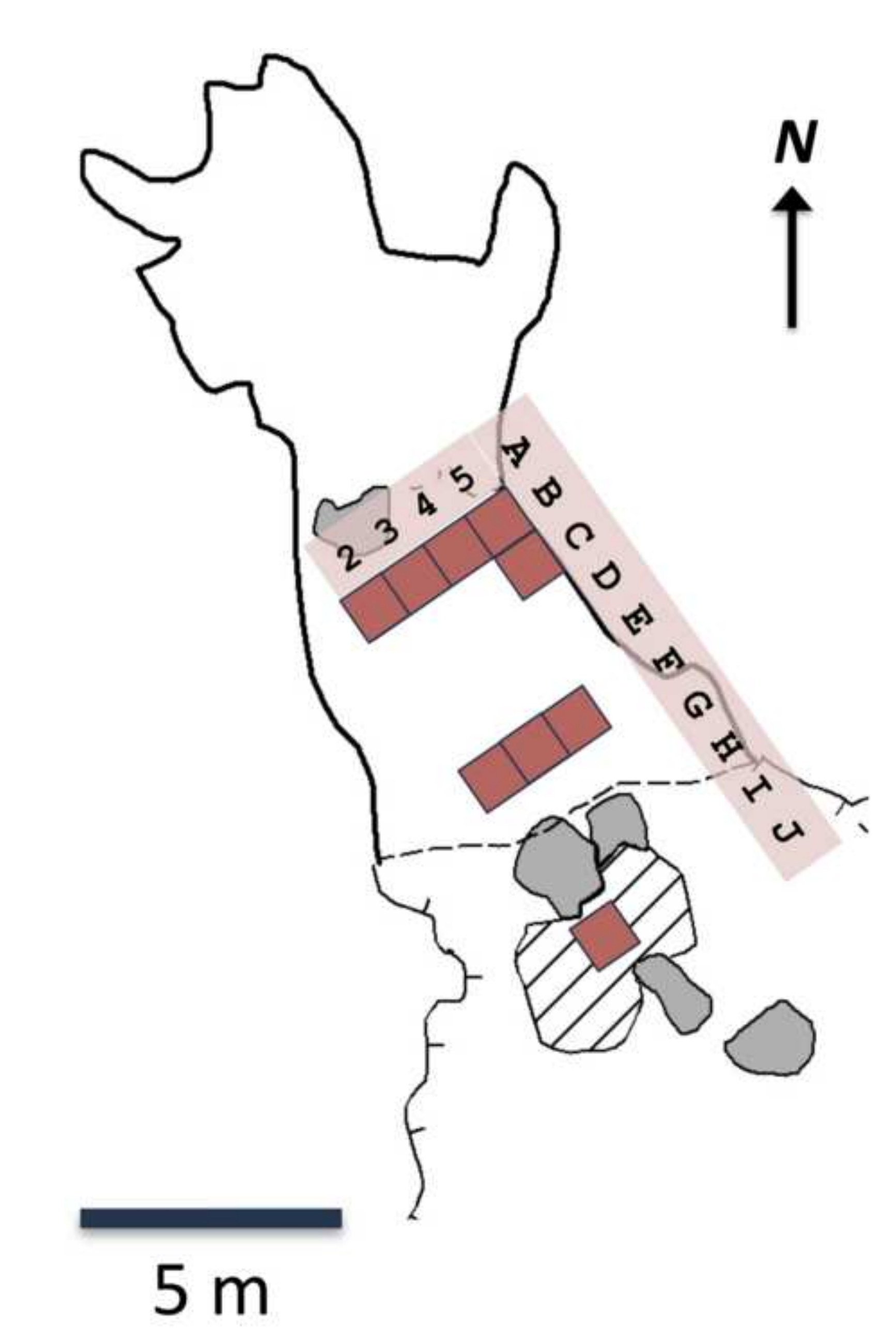

Figure 3

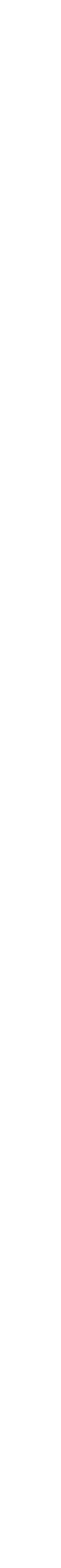

(1)
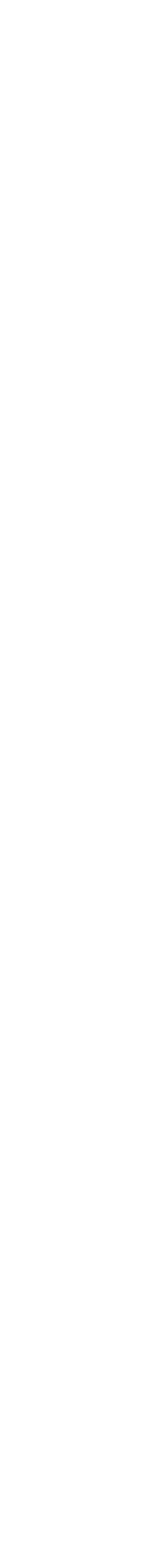


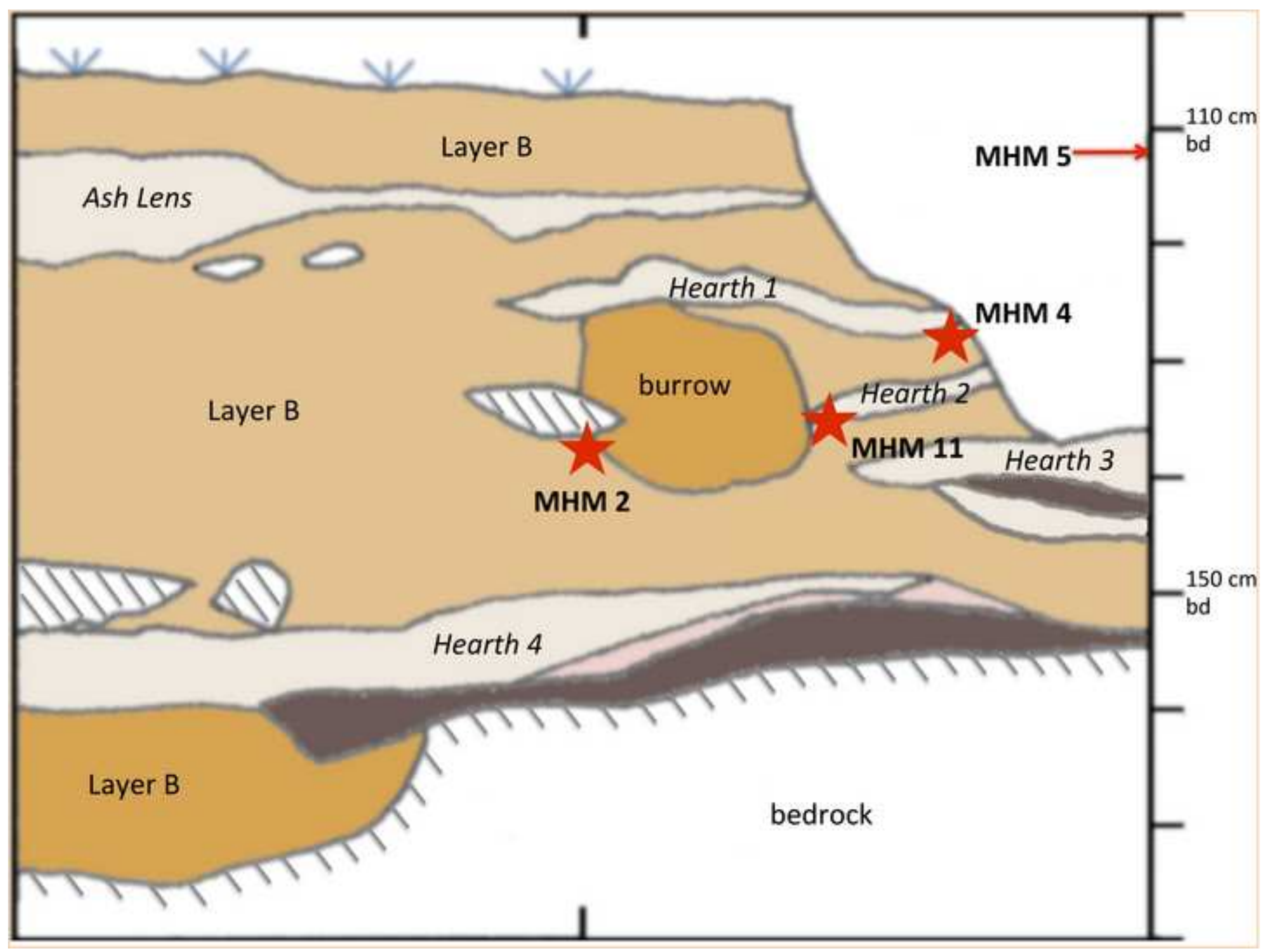



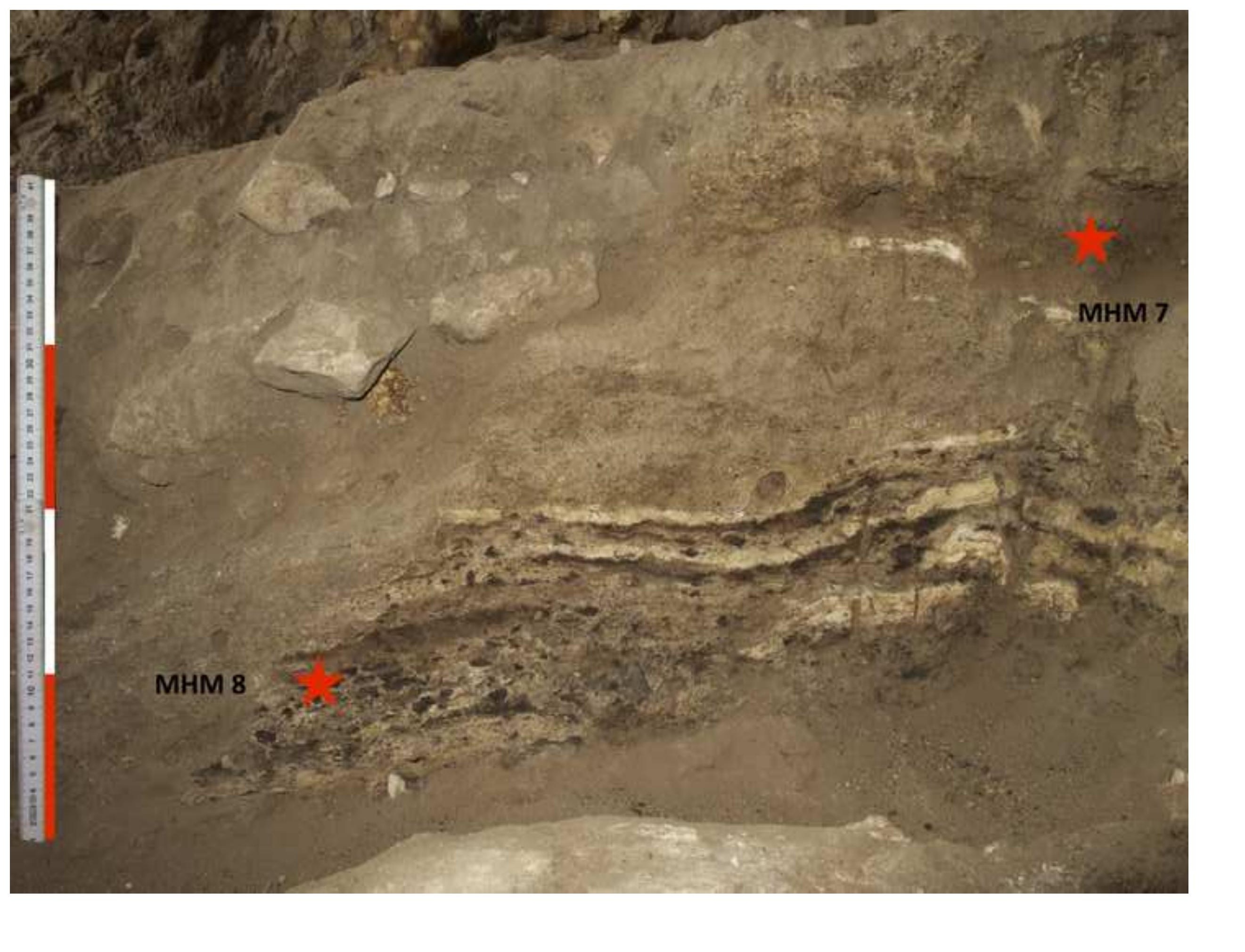

Figure $4 b$
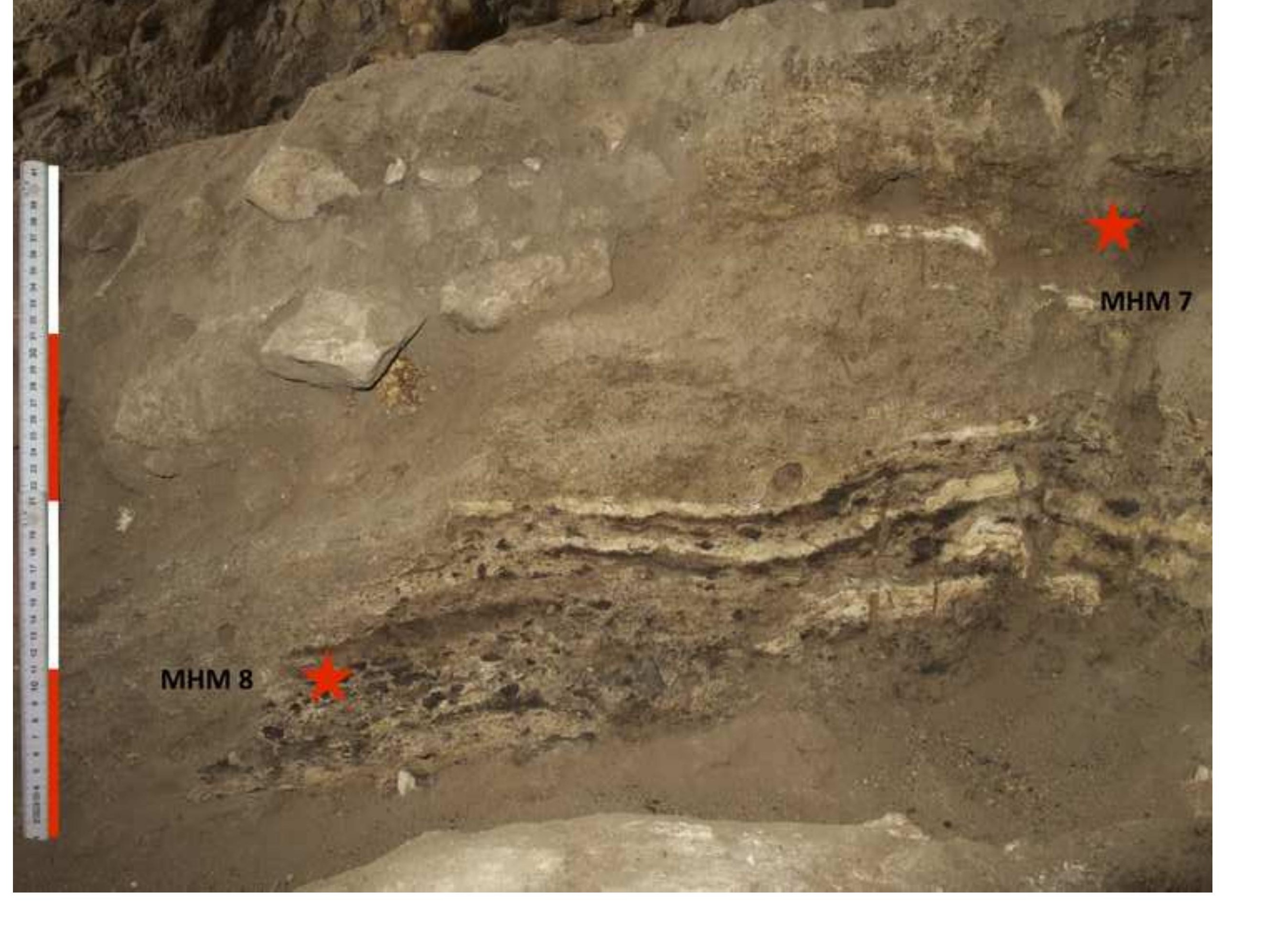


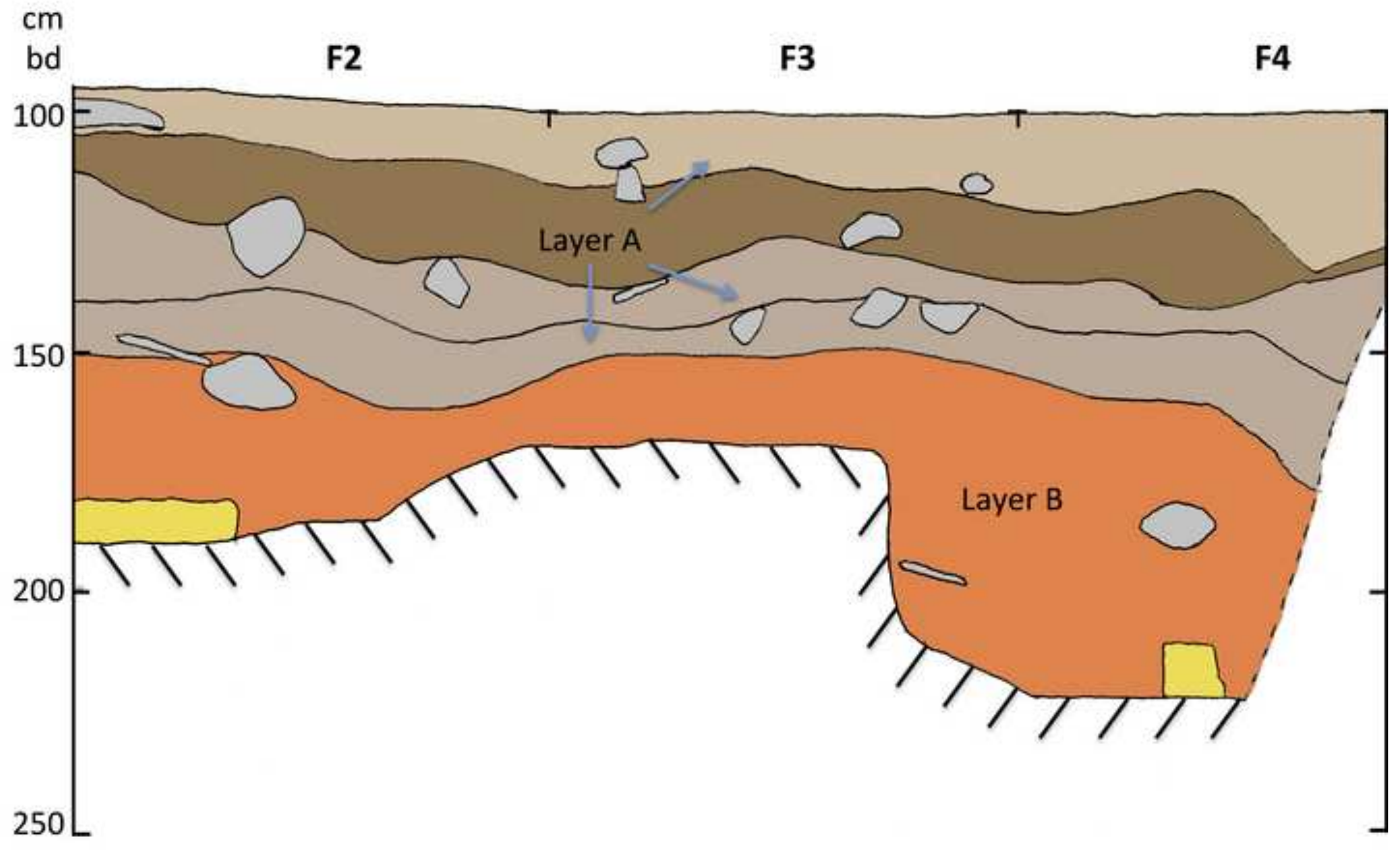



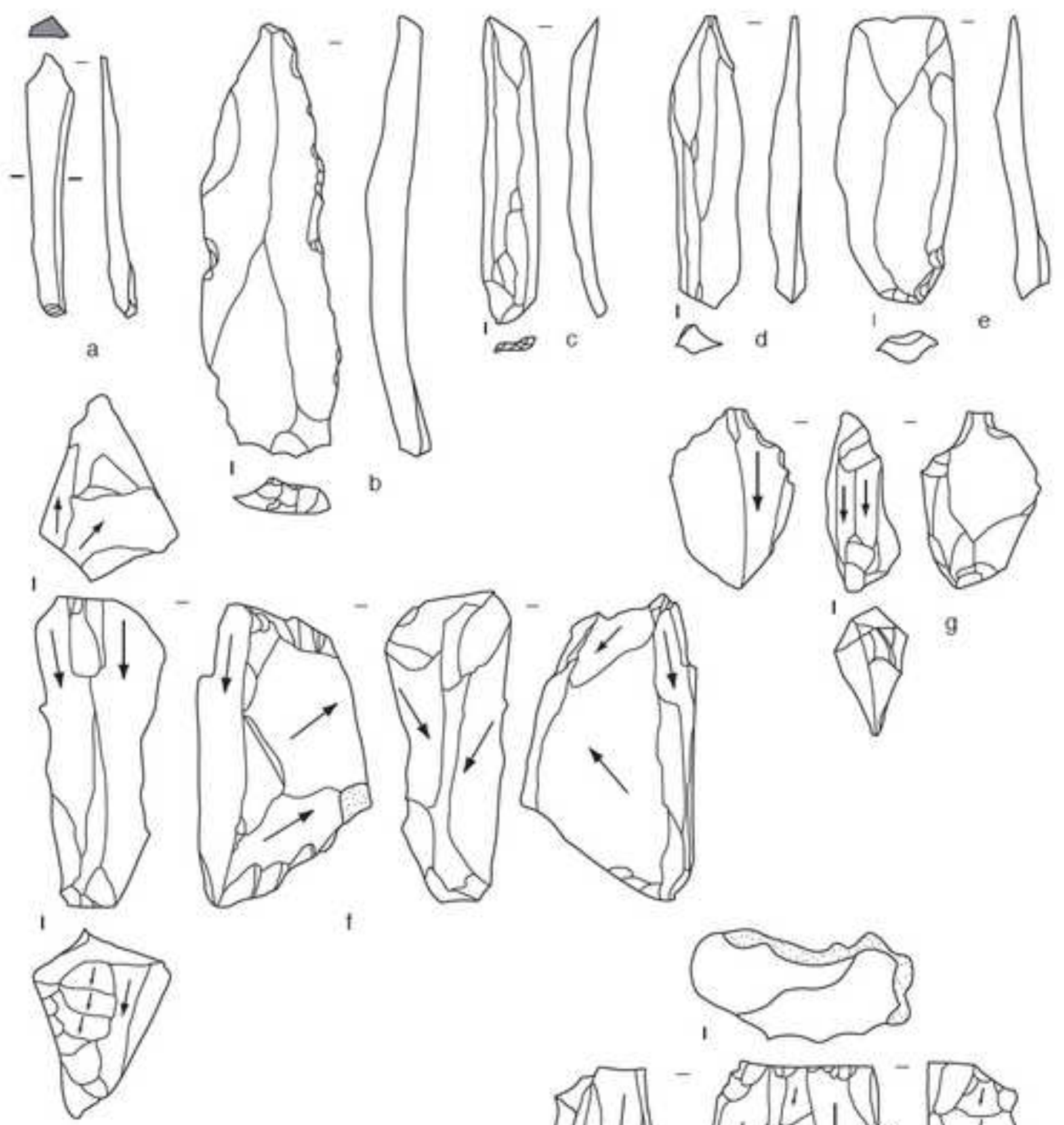

$t$
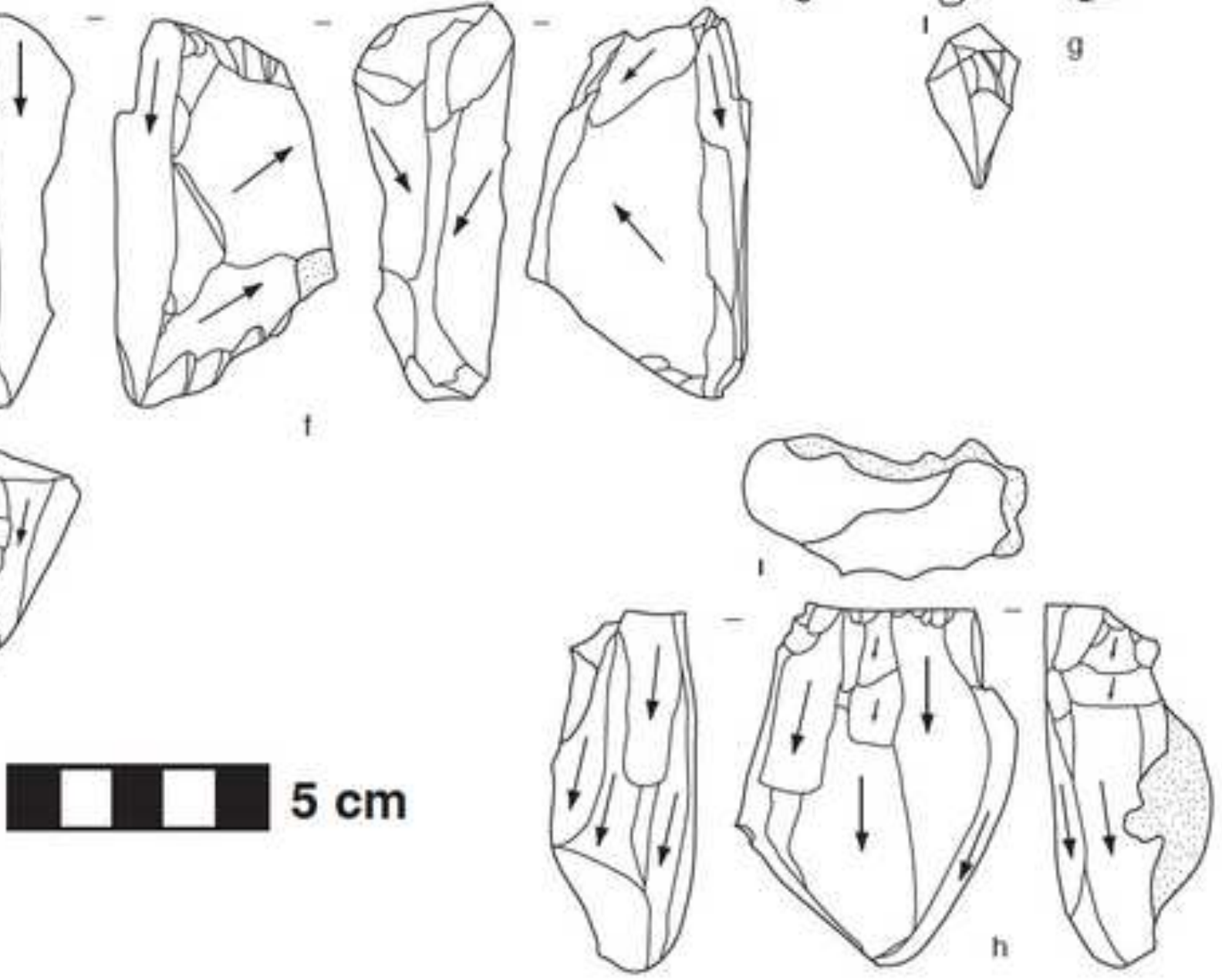

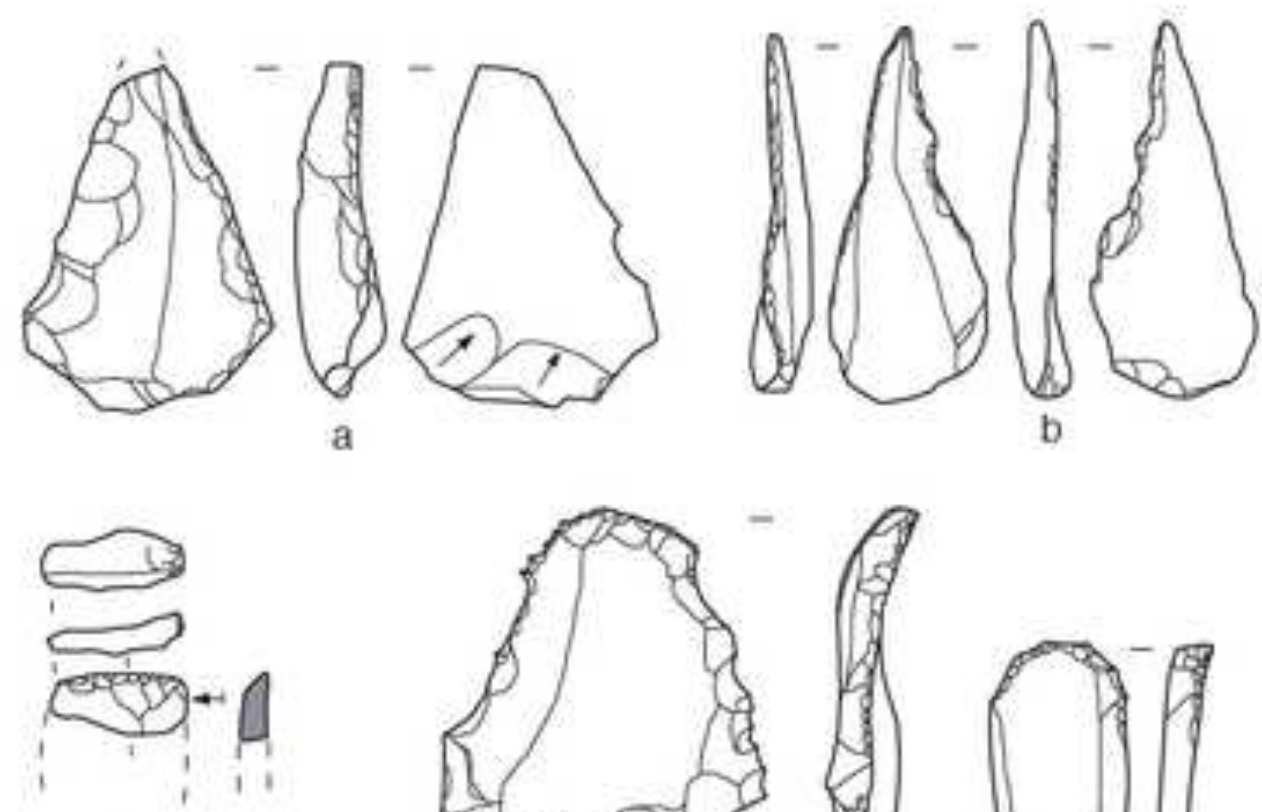

e
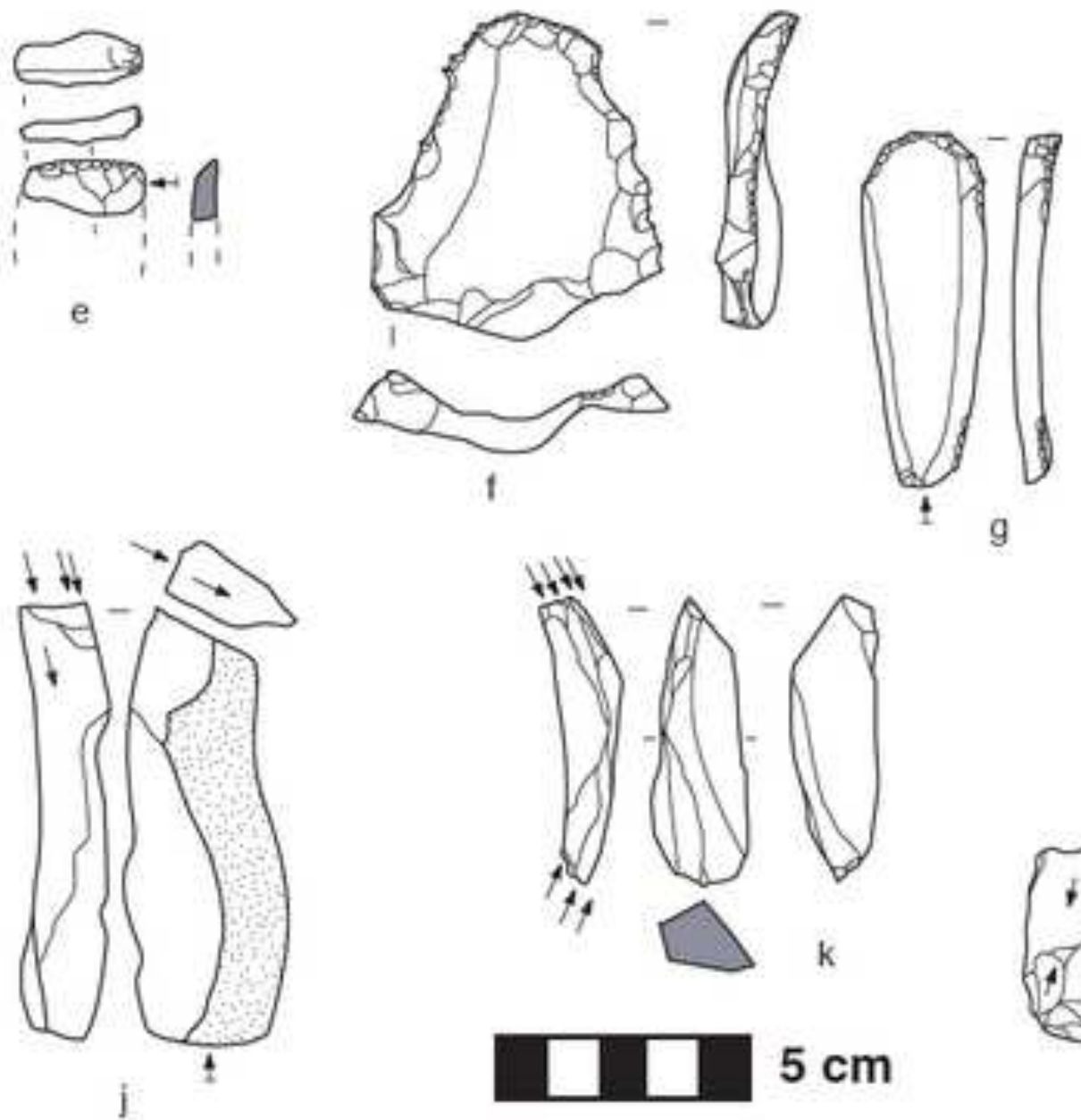

$\square \square 5 \mathrm{~cm}$
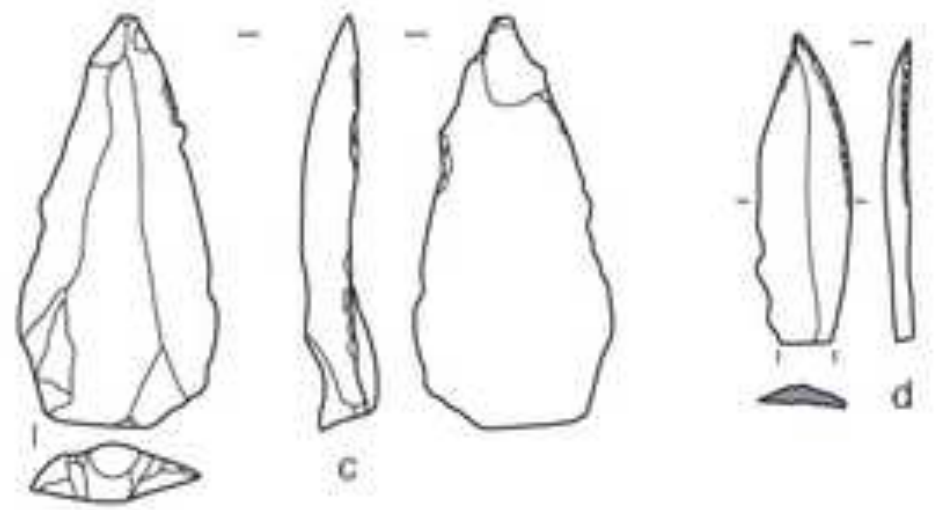
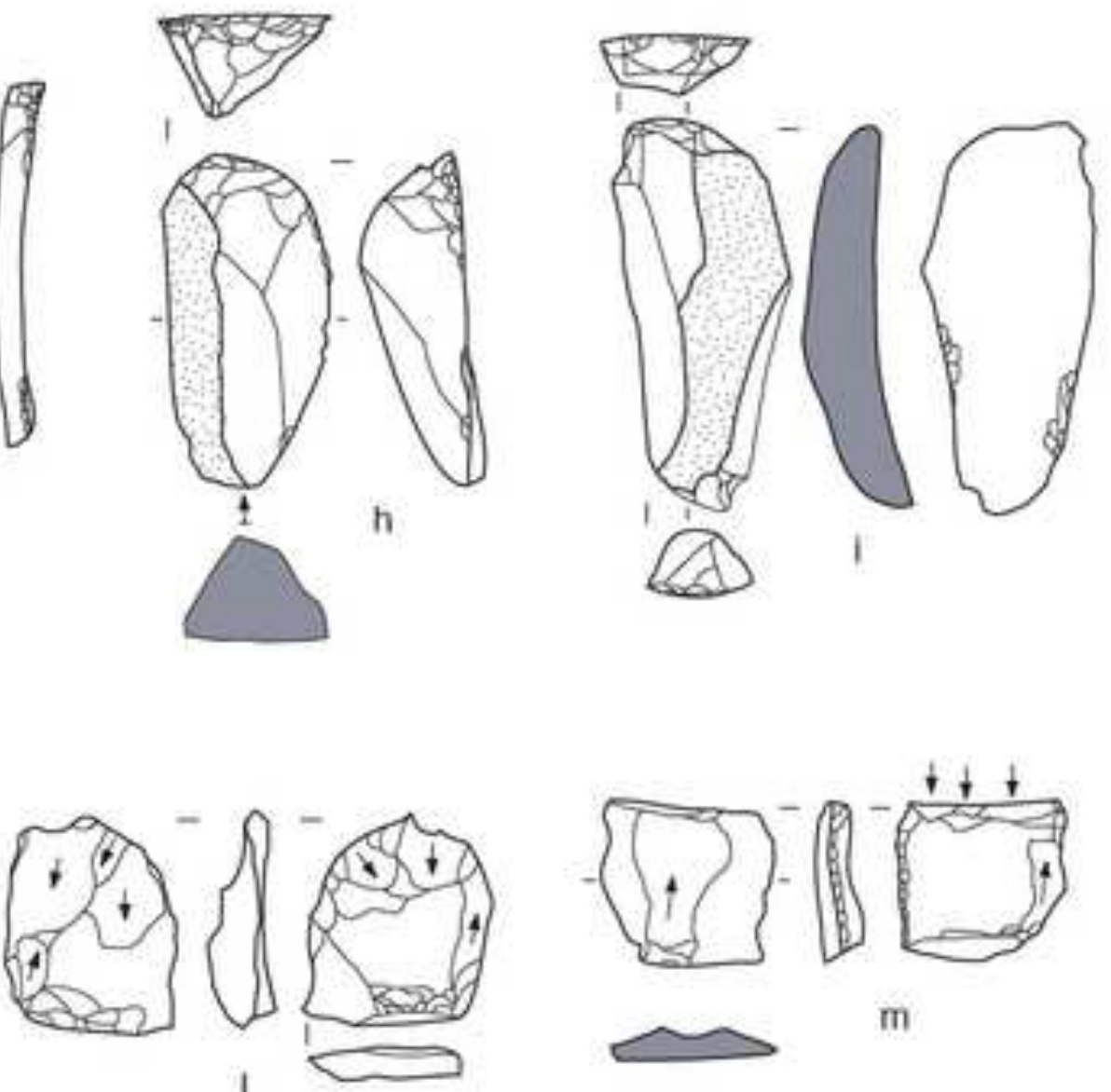

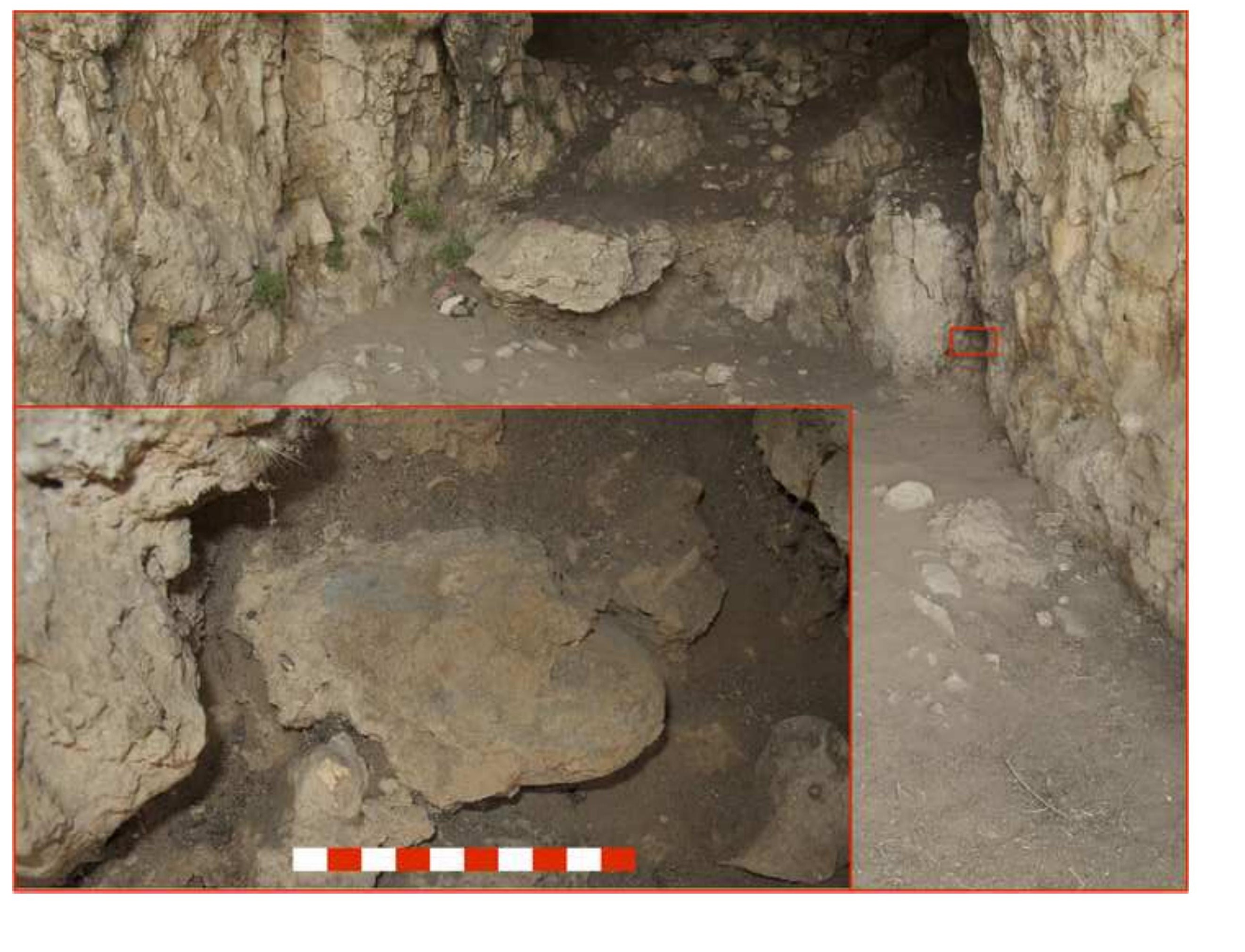


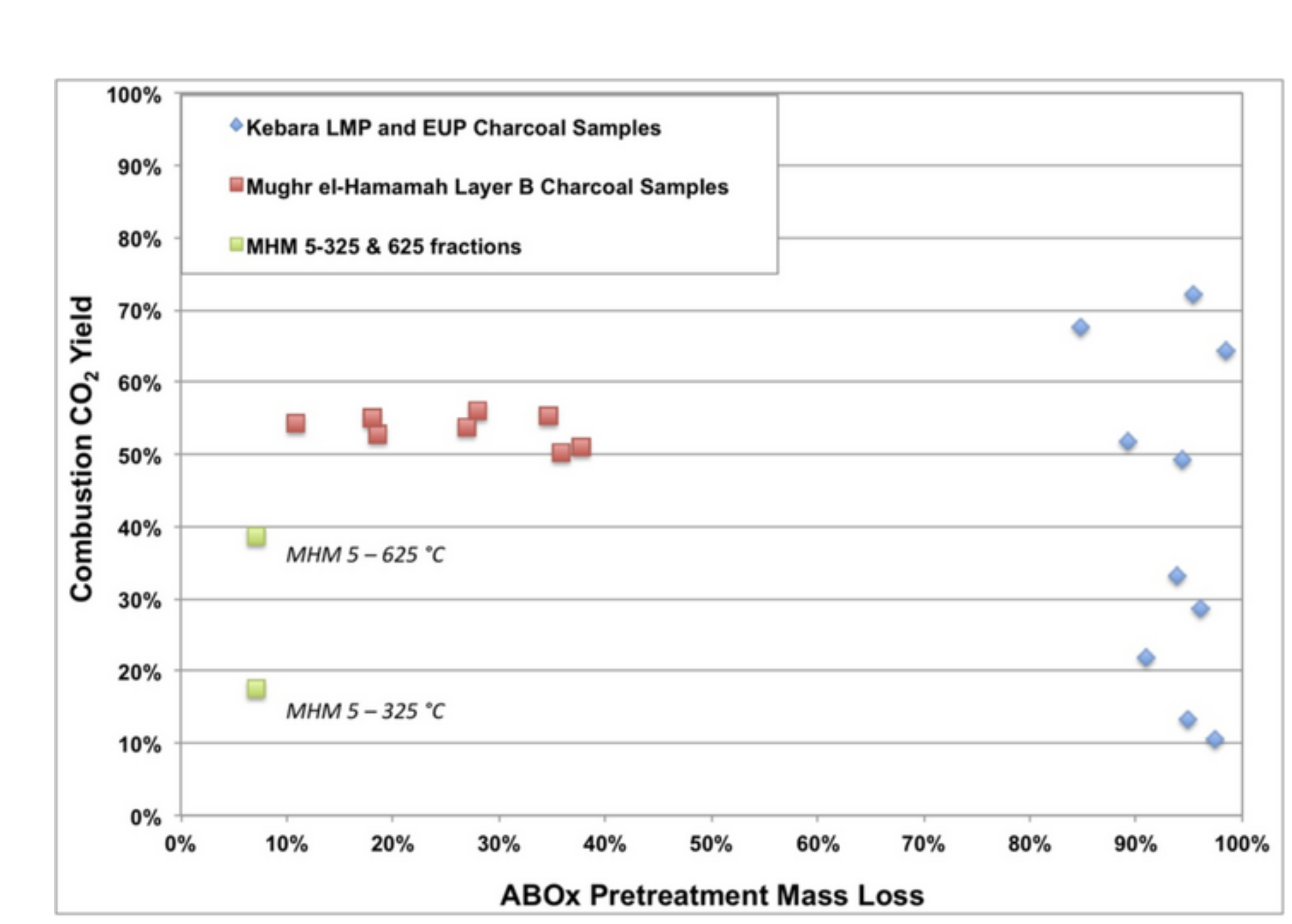




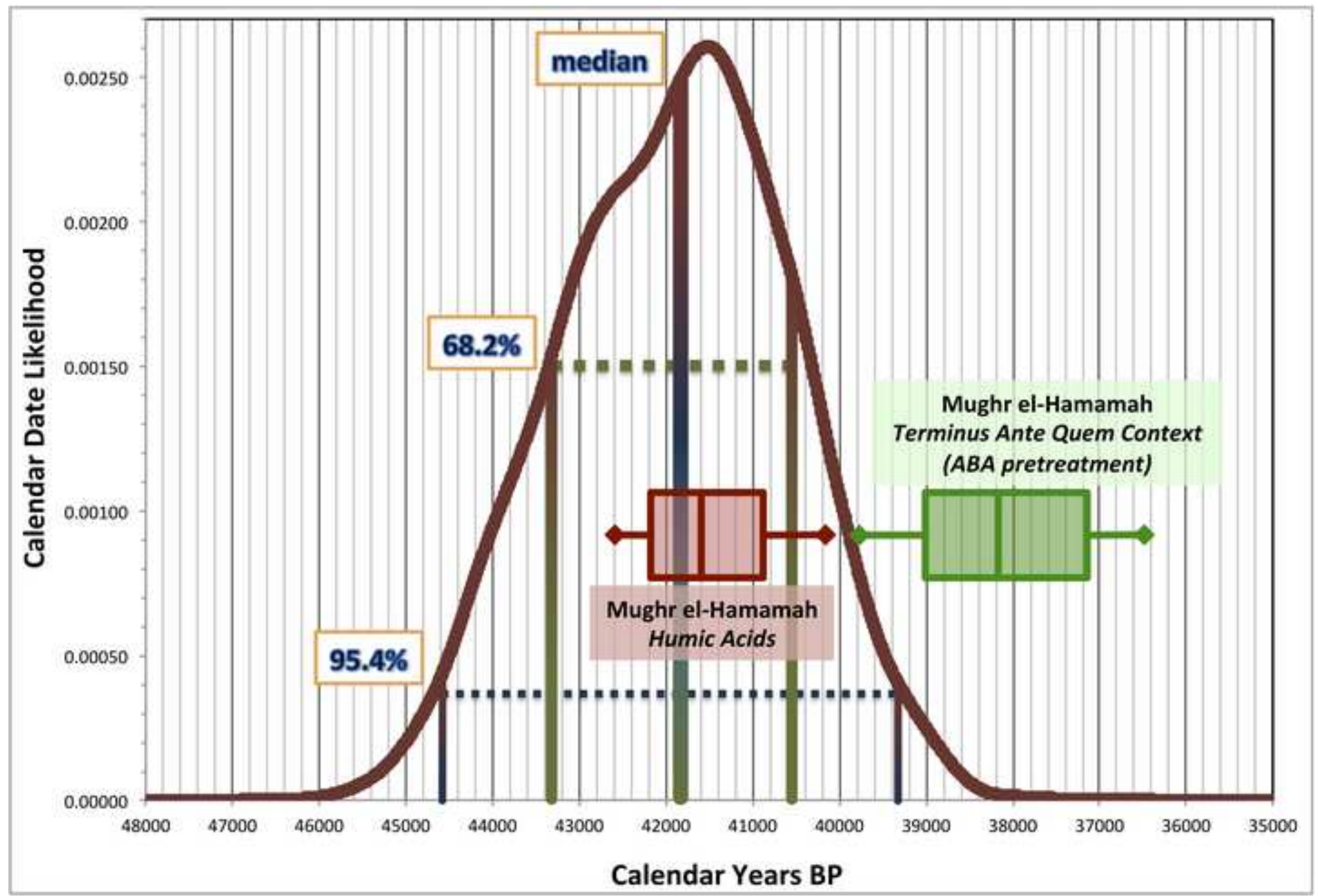

